\title{
Natural Rock Fractures: From Aperture to Fluid Flow
}

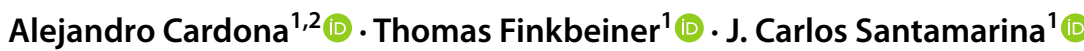

Received: 20 October 2020 / Accepted: 26 June 2021 / Published online: 7 August 2021

(c) The Author(s) 2021

\begin{abstract}
Fractures provide preferential flow paths and establish the internal "plumbing" of the rock mass. Fracture surface roughness and the matedness between surfaces combine to delineate the fracture geometric aperture. New and published measurements show the inherent relation between roughness wavelength and amplitude. In fact, data cluster along a power trend consistent with fractal topography. Synthetic fractal surfaces created using this power law, kinematic constraints and contact mechanics are used to explore the evolution of aperture size distribution during normal loading and shear displacement. Results show that increments in normal stress shift the Gaussian aperture size distribution toward smaller apertures. On the other hand, shear displacements do not affect the aperture size distribution of unmated fractures; however, the aperture mean and standard deviation increase with shear displacement in initially mated fractures. We demonstrate that the cubic law is locally valid when fracture roughness follows the observed power law and allows for efficient numerical analyses of transmissivity. Simulations show that flow trajectories redistribute and flow channeling becomes more pronounced with increasing normal stress. Shear displacement induces early aperture anisotropy in initially mated fractures as contact points detach transversely to the shear direction; however, anisotropy decreases as fractures become unmated after large shear displacements. Radial transmissivity measurements obtained using a torsional ring shear device and data gathered from the literature support the development of robust phenomenological models that satisfy asymptotic trends. A power function accurately captures the evolution of transmissivity with normal stress, while a logistic function represents changes with shear displacement. A complementary hydro-chemo-mechanical study shows that positive feedback during reactive fluid flow heightens channeling.
\end{abstract}

Keywords Fractures $\cdot$ Flow $\cdot$ Roughness $\cdot$ Shear $\cdot$ Stress $\cdot$ Aperture $\cdot$ Rock $\cdot$ Transmissivity

\section{List of symbols}

$A_{c}(\sigma)\left(\mathrm{m}^{2}\right) \quad$ True fracture contact area

$A_{f}\left(\mathrm{~m}^{2}\right) \quad$ Apparent fracture area

$A_{H} \quad$ Fitting parameter in Lomize's hydraulic aperture model

$A_{s} \quad$ Fitting parameter in Tezuka's fracture transmissivity—shear displacement model

Alejandro Cardona

alejandro.cardonaramirez@kaust.edu.sa

Thomas Finkbeiner

thomas.finkbeiner@kaust.edu.sa

J. Carlos Santamarina

carlos.santamarina@kaust.edu.sa

1 Energy Resources and Petroleum Engineering, King Abdullah University of Science and Technology KAUST, Thuwal 23955-6900, Saudi Arabia

2 Present Address: Institute for Geophysics, Jackson School of Geosciences, The University of Texas at Austin, Austin, TX, USA

$\begin{array}{ll}B_{H} & \begin{array}{l}\text { Fitting parameter in Partir and Cheng's } \\ \text { hydraulic aperture model }\end{array} \\ B_{s}(\mathrm{MPa}) & \begin{array}{l}\text { Fitting parameter in Tezuka's fracture } \\ \text { transmissivity - shear displacement model }\end{array} \\ C_{H} & \begin{array}{l}\text { Fitting parameter in Partir and Cheng's } \\ \text { hydraulic aperture model }\end{array} \\ c & \text { Ratio true contact area to fracture apparent } \\ & \text { area } \\ c_{f}(\mathrm{~m} / \mathrm{N}) & \text { Gouge production coefficient } \\ C_{p}\left(\mathrm{~m}^{-1}\right) & \text { Roughness peak curvature } \\ f_{0} & \text { Fitting parameter in Plesha's dilation } \\ G^{-1}\left(\mathrm{~m}^{3}\right) & \text { model } \\ h_{G}(\mathrm{~m}) & \text { Power spectral density } \\ h_{H}(\mathrm{~m}) & \text { Geometric aperture } \\ h_{H O}(\mathrm{~m}) & \text { Hydraulic aperture } \\ \mathrm{JRC}_{\mathrm{mob}} & \text { Hydraulic aperture at zero normal stress } \\ K & \text { Equivalent joint roughness coefficient for } \\ k\left(\mathrm{~s}^{-1}\right) & \text { shear }\end{array}$




\begin{tabular}{|c|c|}
\hline$m$ & Roughness mean slope \\
\hline$N$ & Number of digital values in a signal \\
\hline$P(\mathrm{MPa})$ & Fluid pressure \\
\hline$R_{a}(\mathrm{~m})$ & Average roughness \\
\hline$R M S(\mathrm{~m})$ & Roughness root mean square \\
\hline$s(\tau)$ & Semivariogram \\
\hline$s_{G}(\mathrm{~m})$ & $\begin{array}{l}\text { Standard deviation of the geometric } \\
\text { aperture }\end{array}$ \\
\hline$S_{k}$ & Roughness skewness \\
\hline$T\left(\mathrm{~cm}^{2} / \mathrm{s}\right)$ & Fracture transmissivity \\
\hline$T_{c}\left(\mathrm{~cm}^{2} / \mathrm{s}\right)$ & Characteristic fracture transmissivity \\
\hline$T_{\sigma 0}\left(\mathrm{~cm}^{2} / \mathrm{s}\right)$ & Transmissivity asymptote as $\sigma^{\prime} \rightarrow 0$ \\
\hline$T_{\sigma \infty}\left(\mathrm{cm}^{2} / \mathrm{s}\right)$ & Transmissivity asymptote as $\sigma^{\prime} \rightarrow \infty$ \\
\hline$T_{\delta 0}\left(\mathrm{~cm}^{2} / \mathrm{s}\right)$ & Transmissivity asymptote as $\delta_{s} \rightarrow 0$ \\
\hline$T_{\delta \infty}\left(\mathrm{cm}^{2} / \mathrm{s}\right)$ & Transmissivity asymptote as $\delta_{s} \rightarrow \infty$ \\
\hline$W_{p}\left(\mathrm{~N} . \mathrm{m} / \mathrm{m}^{2}\right)$ & Plastic shear work \\
\hline$X(\lambda)(\mathrm{m})$ & Asperity amplitude for a given wavelength \\
\hline$z_{i}(\mathrm{~m})$ & Asperity height \\
\hline$\alpha\left(\mathrm{m}^{3}\right)$ & Spectral density at $\lambda=1 \mathrm{~m}$ \\
\hline$\beta$ & $\begin{array}{l}\text { Power spectral density sensitivity to } \\
\text { wavelength }\end{array}$ \\
\hline$\delta_{n}(\mathrm{~mm})$ & Fracture normal displacement \\
\hline$\delta_{s}(\mathrm{~mm})$ & Fracture shear displacement \\
\hline$\delta_{s c}(\mathrm{~mm})$ & Characteristic shear displacement \\
\hline$\Delta x(\mathrm{~m})$ & Sampling interval \\
\hline$\phi(\lambda)$ & Asperity phase \\
\hline$\gamma$ & $\begin{array}{l}\text { Fracture sensitivity to effective normal } \\
\text { stress }\end{array}$ \\
\hline$\eta$ & Fracture sensitivity to shear displacement \\
\hline$\lambda(\mathrm{m})$ & Asperity wavelength \\
\hline$\mu(\mathrm{Pa} \mathrm{s})$ & Fluid viscosity \\
\hline$\mu_{G}(\mathrm{~m})$ & Mean of the geometric aperture \\
\hline$\theta$ & $\begin{array}{l}\text { Fourier transform of the aperture correla- } \\
\text { tion function }\end{array}$ \\
\hline$\rho\left(\mathrm{kg} / \mathrm{m}^{3}\right)$ & Fluid density \\
\hline$\sigma(\mathrm{MPa})$ & Normal stress \\
\hline$\sigma^{\prime}(\mathrm{MPa})$ & Effective normal stress \\
\hline$\sigma_{\text {yield }}(\mathrm{MPa})$ & Yield stress of the material \\
\hline$\sigma_{c}(\mathrm{MPa})$ & Characteristic normal stress \\
\hline$\tau$ & Discrete correlation distance \\
\hline$\zeta$ & $\begin{array}{l}\text { Fitting parameter in Swan's fracture trans- } \\
\text { missivity—normal stress model }\end{array}$ \\
\hline
\end{tabular}

\section{Introduction}

Fractures provide preferential flow paths that define the rock mass internal "plumbing", especially in low matrix-permeability rocks. Therefore, the rock mass hydraulic response results from the fracture density, orientation, and the stresssensitive fracture transmissivity (Barton et al. 1995; Zimmerman and Bodvarsson 1996). In turn, fluid conduction in fractured rock masses affects the pore pressure distribution and effective stress field, flow rates, and immiscible fluid invasion (Aydin 2000; Shin and Santamarina 2019). Consequently, fracture transmissivity is critical to the engineering design of geotechnical structures, resource recovery, contaminant transport, and the geological storage of nuclear waste or $\mathrm{CO}_{2}$.

The void space between two rough fracture surfaces governs fracture transmissivity (Hakami and Larsson 1996; Olsson and Barton 2001), controls the fracture deformation during normal loading (Tsang and Witherspoon 1981; Brown and Scholz 1986), and determines fracture dilation during shear displacement (Patton 1966; Saeb and Amadei 1992; Lee and Cho 2002).

This study explores the effects of surface roughness on geometric aperture and hydraulic transmissivity as a function of normal stress and shear displacement. The manuscript is organized into three complementary sections: geometric aperture, contact mechanics, and flow. Each section includes an overview of previous research, provides new laboratory data, and advances analyses toward the enhanced understanding and modeling of fracture transmissivity. Altogether, the different sections provide new physical insight into fracture transmissivity and the effects of normal stress and shear displacement. The concise presentation is complemented by seminal references for further details.

\section{Geometric Aperture: Fracture Roughness and Matedness}

Rock characteristics and fracture genesis define surface roughness and the matedness or geometric correlation between fracture surfaces. For example, fresh tensile fractures exhibit higher degrees of matedness than shear fractures (Odling 1994; Al-Fahmi et al. 2018). Either cross-grain or inter-granular fracture propagation and frictional wear dominate roughness at the sub-meter scale, while kinematics, fracture convergence and the coalescence of secondary fractures control roughness at larger scales (Lee and Bruhn 1996; Candela et al. 2012; Brodsky et al. 2016). Furthermore, post-genesis stress changes and associated displacements, asperity crushing, cataclasis, creep and ploughing, fines generation, chemical dissolution and precipitation alter the void space and lead to complex hydro-thermochemo-mechanically coupled phenomena (Berkowitz 2002; Rutqvist et al. 2002; Taron et al. 2009).

The "geometric aperture" $h_{G}(\mathrm{~m})$ reflects both the roughness of the two rock surfaces in contact and the matedness between them (Barton et al. 1985). The direct measurement of aperture in the laboratory relies on resin injection and casting, or tomographic imaging based on X-rays or nuclear magnetic resonance NMR. However, limitations in these techniques such as specimen size, partial fluid invasion, 
volume changes during curing, and low resolution limited by specimen size hinder the accuracy of casting and imaging methods (Pyrak-Nolte et al. 1987; Sharifzadeh et al. 2008; Keller 1998; Dijk et al. 1999; Bertels et al. 2001). On the other hand, indirect methods measure the roughness of the two fracture surfaces and infer geometric aperture numerically for a given relative positioning of the two surfaces (Brown and Kranz 1986; Lanaro 2000; Vogler et al. 2018).

The following sub-sections introduce the tested materials and roughness measurements, present analyses based on power spectra either compiled from the literature or computed from the measurements and digitized JRC profiles, and advance a protocol to create synthetic fracture surfaces using power spectra information. These synthetic surfaces, combined with fracture matedness define the fracture aperture.

\subsection{Fracture Surface Roughness-Measurement}

Empirical approaches simplify the characterization of surface roughness for engineering analyses, however, they are not adequate for quantitative aperture studies. The qualitative joint roughness coefficient JRC is a salient example (Barton 1973; Beer et al. 2002).
Detailed fracture roughness measurement techniques use either contact probes or optical techniques (Leach 2011; Tarolli 2014). In particular, optical methods from field devices such as LIDAR to laboratory electron microscopy span 8-10 orders of magnitude in scale, and often involve laser scanning or light interferometry.

We measured the surface roughness of natural and artificially fractured limestones using a table-top chromatic confocal interferometer (Nanovea ST400). Smooth surfaces were produced using a polishing device (Kent KGS618), whereas sandblasted surfaces used a water-sand jet (MBA Wet Blaster). We also measured the roughness of a natural fracture present in a limestone core. Insets in Fig. 1 present the scans obtained for $15 \times 15 \mathrm{~mm}$ polished and sandblasted limestone surfaces and a $10 \times 10 \mathrm{~mm}$ natural fracture surface. The height resolution is $0.2 \mu \mathrm{m}$. The peak-to-valley distance ranges from $60 \mu \mathrm{m}$ for the polished surface to $600 \mu \mathrm{m}$ for the sandblasted and natural surfaces.

\subsection{Fracture Surface Roughness-Analysis}

The analysis of roughness data involves amplitude and texture descriptors. Amplitude refers to elevation normal to the mean fracture plane, while texture considers patterns on the

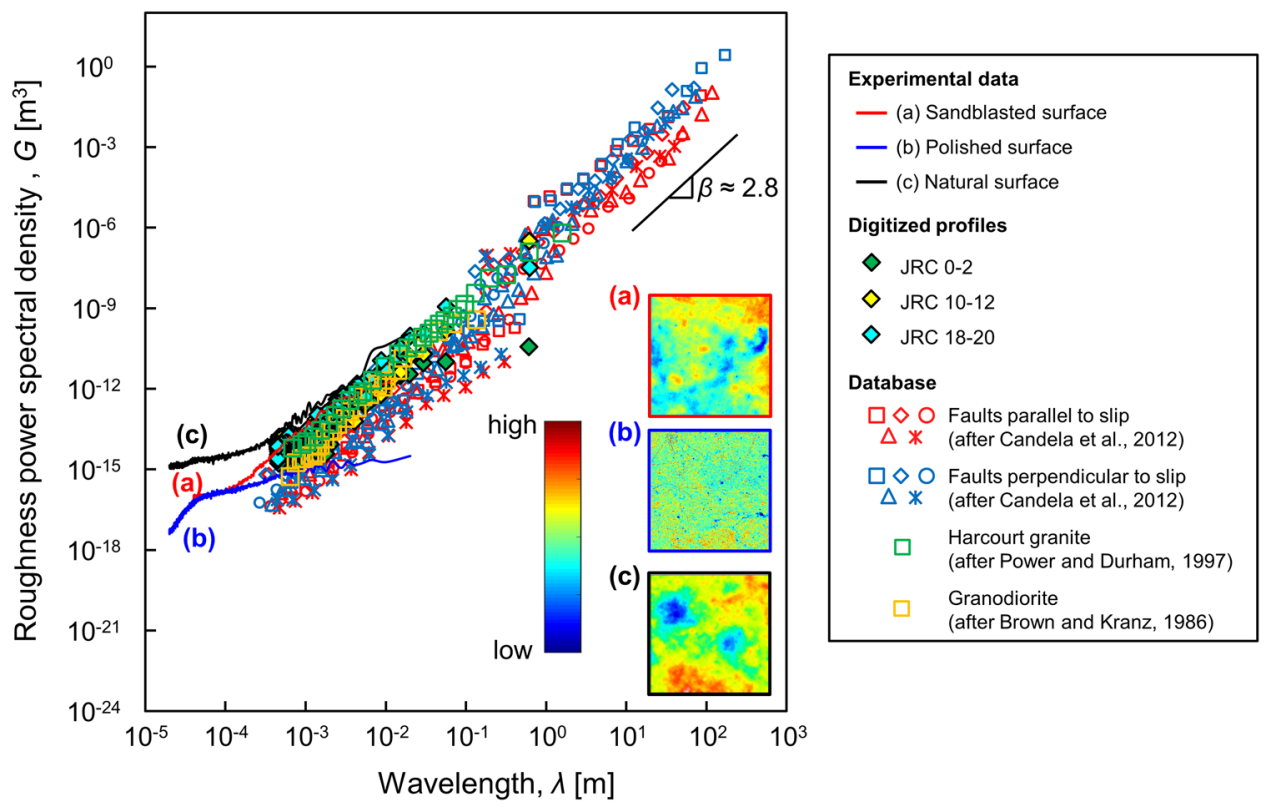

Fig. 1 Roughness power spectral density $G(\lambda)$ derived from 1D fractures and faults profiles. The wavelength $\lambda$ scale spans eight orders of magnitude. As the legend on the right indicates, empty markers correspond to published data (references below) filled markers are data from digitized JRC-profiles, and solid lines correspond to the average power spectrum of the three carbonate specimens profiles tested in this study. Insets correspond to interferometer surface scans of three tested specimens: a $15 \times 15 \mathrm{~mm}$ sandblasted specimen (color-bar indicates surface roughness and varies from 0 to $600 \mu \mathrm{m}$ ); b $15 \times 15 \mathrm{~mm}$ polished specimen (roughness color-bar varies from 0 to $60 \mu \mathrm{m}$ ); $\mathbf{c}$
$10 \times 10 \mathrm{~mm}$ natural fracture (color-bar varies from 0 to $600 \mu \mathrm{m}$ ). Empty red markers indicate profiles of exhumed faults surfaces parallel to slip and blue markers show profiles perpendicular to the slip direction. Squares: Magnola, Diamonds: Corona Heights; Triangles: Vuache-Sillingly; Circles: Dixie Valley; Star: Bolu (after Candela et al. 2012). Green empty squares are a natural surface in Harcourt Granite (after Power and Durham 1997). Orange empty squares correspond to a granodiorite from Fenton Hill, New Mexico (after Brown and Kranz 1986) 
plane. Table 1 summarizes statistical parameters that are used to evaluate amplitude and texture. These parameters readily reveal the challenges in roughness characterization; for example, slope and curvature values are not unique but depend on the sampling interval and computation method, and amplitude distributions depend on specimen length and suggest nonstationary randomness (Majumdar and Bhushan 1990; Sayles and Thomas 1978). In fact, roughness studies highlight the inherent link between roughness values, the measurement scale, and resolution.

The surface roughness power spectral density provides unbiased amplitude and texture information (Power and Tullis 1991; Jacobs et al. 2017). We followed a five-step procedure to compute the surface roughness power spectrum: (1) measure 500 parallel roughness profiles on the specimen surface (lateral spacing between linear scans $=20 \mu \mathrm{m}$ ), (2) remove the linear trend for each profile, (3) window the detrended signal with a $3 \%$ cosine taper to reduce leakage, (4) compute the normalized power spectral density $G\left(\mathrm{~m}^{3}\right)$ using the Fast Fourier Transform and (5) average the spectra for the 500 parallel profiles to obtain an equivalent 1D representation. Inherently, this procedure imposes a high-pass filter whereby wavelengths longer than the specimen size are filtered out. Figure 1 shows the roughness power spectral densities for three limestone surfaces: polished, sandblasted and a natural fracture.

\subsection{Fracture Surface Roughness-Database}

We compiled an extensive database of power spectra for rock surfaces in various lithologies including carbonates and granites. Surfaces involved exhumed faults parallel and perpendicular to slip (i.e., meter scale), laboratory specimens (i.e., centimeter scale), and digitized JRC fracture profiles. Laboratory specimens included fractures recovered from cores, created during strength testing, or sawed-polished, and sandblasted surfaces (measured in this study-Sect. 2.1). Figure 1 presents spectral densities as a function of wavelength $\lambda(\mathrm{m})$ for the complete dataset. The various datasets involved different devices (i.e., LiDAR, profilometers, and interferometers) and spectral data analyses, yet, most of the data collapses onto a narrow trend. In fact, the roughness power spectrum of laboratory and natural fractures and faults follows a power law with respect to wavelength:

$G(\lambda)=\alpha\left(\frac{\lambda}{[m]}\right)^{\beta}$

The power law implies a fractal surface topography (Mandelbrot et al. 1984; Katz and Thompson 1985; Power and Durham 1997). The parameters for the overall trend are $\alpha=6 \times 10^{-7} \mathrm{~m}^{3}$ and $\beta=2.8$, where the $\alpha$-factor is the spectral density for $\lambda=1 \mathrm{~m}$, and the $\beta$-exponent is related to the fractal dimension (Brown 1995).

The fractal nature of surface roughness extends from geological features (e.g., strata in sedimentary rocks and faults) to the grain/crystal scale. Indeed, data in Fig. 1 suggest that this power law relationship remains valid over six orders of magnitude, and provides a convenient framework to relate laboratory measurements to the field scale.

We analyzed the individual roughness trends for all specimens in the database. In all cases, spectral densities fall along the main power trend in Fig. 1, but exhibit a range of $\alpha$-factors $\left[2 \times 10^{-10}\right.$ to $7 \times 10^{-4} \mathrm{~m}^{3}$ ] and $\beta$-exponents [1.9-3.0]. The $\alpha$-factor and $\beta$-exponent increase with JRC roughness (for example: $\alpha=2 \times 10^{-8} \mathrm{~m}^{3}$ and $\beta=2.1$ for JRC $0-2$, while $\alpha=4 \times 10^{-7} \mathrm{~m}^{3}$ and $\beta=2.4$ for JRC 18-20). Deviations from the global trend occur at large wavelengths for "smooth" profiles, e.g., $\lambda>10^{-3} \mathrm{~m}$ for our polished limestone surface and $\lambda>10^{-2} \mathrm{~m}$ for the JRC 0-2. These results indicate non-natural smoothness and suggest inherent limitations in the use of artificially roughened specimens to study fracture processes. Similar studies refer to this transition as corner frequency (Chen and Spetzler 1993).

The following sub-section uses this power-law relationship and proposes a methodology to create synthetic fracture surfaces.
Table 1 Amplitude and texture descriptors for fracture roughness (Thomas 1998; Magsipoc et al. 2020)

\begin{tabular}{llll}
\hline Amplitude descriptor & Texture descriptor & \\
\hline Average roughness, $R_{a}$ & $R_{a}=\frac{1}{N} \sum_{i=1}^{N}\left|z_{i}\right|$ & Mean slope, $m$ & $m=\frac{1}{N-1} \sum_{i=1}^{N-1} \frac{z_{i+1}-z_{i}}{\Delta z}$ \\
Root-mean-square, RMS & RMS $=\sqrt{\sum_{i=1}^{N} z_{i}^{2} \frac{1}{N}} \quad$ Peak curvature, $C_{p}$ & $C_{p}=\frac{1}{N-2} \sum_{i=1}^{N-2} \frac{2 z_{i}-z_{i-1}-z_{i+1}}{\Delta z^{2}}$ \\
Skewness, $S_{k}$ & $S_{k}=\frac{1}{N \text { RMS }^{3}} \sum_{i=1}^{N} z_{i}^{3}$ & Semivariogram, $s(\tau)$ & $s(\tau)=\frac{1}{2(N-\tau)} \sum_{i=1}^{N-\tau}\left(z_{i+h}-z_{i}\right)^{2}$ \\
Kurtosis, $K$ & $K=\frac{1}{N \text { RMS }^{4}} \sum_{i=1}^{N} z_{i}^{4}$ &
\end{tabular}




\subsection{Numerical Generation of Rough Surfaces}

The power spectral density $G(\lambda)$ for a given wavelength $\lambda$ is a function of the corresponding sinusoid amplitude $X(\lambda)(\mathrm{m})$ :

$G(\lambda)=\frac{N \Delta x}{4}[X(\lambda)]^{2}$,

where $N$ is the number of digital values in a given profile and $\Delta x(\mathrm{~m})$ the sampling interval. Note that the scaling factor $(N \Delta x / 4)$ in Eq. 2 depends on the selected Fourier pair and transform definition (i.e., one-sided vs. two-sided). Nevertheless, Eqs. 1 and 2 relate amplitudes $X_{u}$ and $X_{v}$ to their corresponding wavelengths $\lambda_{u}$ and $\lambda_{v}$ regardless of the scaling factor

$\frac{X_{u}}{X_{v}}=\left(\frac{\lambda_{u}}{\lambda_{v}}\right)^{\beta / 2}$.

Alternatively, given a signal length $N \cdot \Delta x$, the sinusoid amplitude $X(\lambda)$ for a given wavelength can be computed in terms of the fitted $\alpha$ and $\beta$ parameters

$X(\lambda)=2 \sqrt{\frac{1}{N \Delta x} \alpha\left(\frac{\lambda}{[m]}\right)^{\beta}}$.

The power spectrum lacks phase information, thus we assumed a uniformly distributed random phase $\phi(\lambda)$. Together $X(\lambda)$ and $\phi(\lambda)$ define the fracture roughness in the frequency domain. We imposed a wavelength cutoff of onefifth of the fracture length to avoid the lower order periodicity in computed profiles (i.e., high-pass filtering): this cutoff value is the longest wavelength that does not generate preferentially oriented ridges and valleys (Matsuki et al. 2006; Briggs et al. 2017). Finally, we computed the Inverse Fast Fourier Transform to determine roughness profiles in space. This methodology can be readily extended to 2D surfaces, and both the linear 1D and surface 2D algorithms satisfy Parseval's identity.

\subsection{Matedness}

We created fractures by bringing two rough surfaces together. Perfectly mated fractures have zero geometric aperture, thus null hydraulic transmissivity. Power spectral analyses help assess the characteristic length for surfaces matching, i.e., a mismatched length scale (Glover et al. 1997; Ogilvie et al. 2006). However, the lack of phase information in power spectra means that two surfaces with identical spectra can result in mismatched topography and non-zero apertures. Other matedness descriptors rely on contact area or joint matching coefficient JMC but disregard the wavelength-dependent correlation between the surfaces (Zhao 1997; Grasselli 2001).

\section{Contact Mechanics}

This section combines numerical realizations of fracture surfaces (Sect. 2.4), contact mechanics, and kinematic deformation to anticipate fracture deformation and the resulting aperture during normal loading and shear displacement. The simple yet robust approach proposed herein is physics-based and further validated against experimental data.

\subsection{Normal Stress}

The fracture contact area and stiffness increase and the mean aperture decreases with increasing normal stress (Iwano and Einstein 1995; Nemoto et al. 2009). Some analyses adopt a non-linear elastic contact model whereby the fracture roughness is an assembly of spheres or cylinders (Greenwood et al. 1966; Hopkins et al. 1987). Other analyses assume that fracture surfaces interpenetrate and overlap each other to reach a prescribed displacement, contact area, or fluid transmissivity (Watanabe et al. 2008; Li et al. 2015; Souley et al. 2015). These are inherently non-elastic fracture models and often involve numerical algorithms that incorporate elastoplastic behavior of the contacts (Walsh et al. 2008; Kling et al. 2018).

We adopted the interpenetration model and assumed a perfectly rigid-plastic rock response. Since the true contact area $A_{c}(\sigma)\left(\mathrm{m}^{2}\right)$ is minimal compared to the fracture apparent area $A_{f}\left(\mathrm{~m}^{2}\right)$, we assumed that all contact points reached the yield stress of the material $\sigma_{\text {yield }}(\mathrm{MPa})$; then, equilibrium with the far field normal stress $\sigma(\mathrm{MPa})$ implies:

$\frac{\sigma}{\sigma_{\text {yield }}}=\frac{A_{c}(\sigma)}{A_{f}}$.

The algorithm brings fracture surfaces together by imposing a displacement $\delta_{v}$ until the interpenetration contact area $A_{c}(\sigma)$ is sufficient to resist the applied stress $\sigma$. Figure 2 compares experimental and numerical results for the sandblasted limestone specimen. The fitted yield stress $\sigma_{\text {yield }}=200 \mathrm{MPa}$ exceeds the measured unconfined compressive strength $\mathrm{UCS}=70-90 \mathrm{MPa}$ by a factor of three; this reflects differences in mono-crystal asperities vs. poly-crystal specimens, boundary conditions, and the low aspect ratio of the asperities compared to the 2:1 ratio used for cylindrical specimens during UCS testing (ASTM 2014; Tuncay and Hasancebi 2009). The insets in Fig. 2 illustrate the apertures computed at $0 \mathrm{MPa}\left(\delta_{v}=0 \mathrm{~mm}\right)$ and $12 \mathrm{MPa}\left(\delta_{v} \approx 0.2 \mathrm{~mm}\right)$. The preferential deformation around edges reflects the global convex geometry observed in sandblasted specimens. 


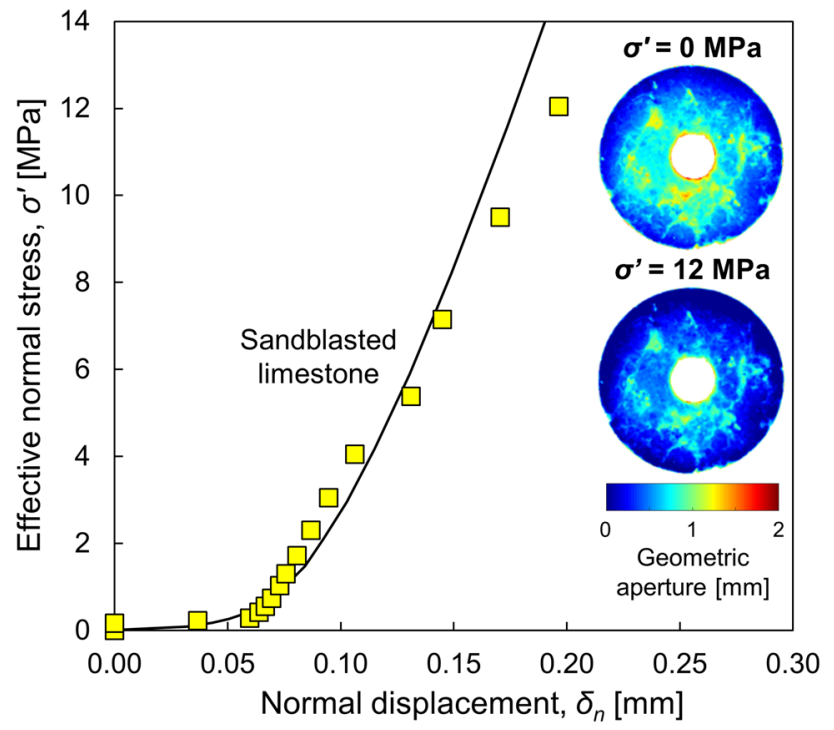

Fig. 2 Fracture normal displacement data due to applied normal stress. Sandblasted limestone specimen (yellow markers). Predicted response (continuous line): the rigid-plastic contact model assumes a yield stress of $200 \mathrm{MPa}$. Insets reflect aperture maps computed at $0 \mathrm{MPa}\left(\delta_{v}=0 \mathrm{~mm}\right)$ and $12 \mathrm{MPa}\left(\delta_{v} \approx 0.2 \mathrm{~mm}\right)$, respectively

We explore the effect of normal stress on aperture size distribution using numerically generated surfaces. Figure $3 \mathrm{a}$ shows the distribution of local aperture for a normally compressed fracture; Fig. 3b shows mean trends computed from 1000 unmated synthetic fracture realizations (following the approach described in Sect. 2.4). Increments in normal stress shift the aperture size distribution toward smaller values; the cutoff at zero aperture corresponds to the true contact area $A_{c}(\sigma)$. Truncated Gaussian distributions properly represent the computed histograms in all cases tested as part of this study (see also Barr and Sherrill 1999; Xiong et al. 2018).

\subsection{Shear Displacement}

Shear-induced dilation and contraction are a consequence of surface roughness and initial matedness, asperity overriding, roughness wear, and degradation, and the consequent progressive generation of gouge material. The normal stress on the fracture surface determines the tradeoff between dilation during asperity overriding and asperity breakage (Barton 1973; Gutierrez et al. 2000). Typical normal versus shear displacement behavior exhibits some initial contraction followed by dilation toward an asymptotic aperture. The dilatancy rate is maximum at peak shear strength. Existing models attempt to capture these effects through geometrical descriptors, spectral information, or JRC-based qualifiers (Grasselli et al. 2002; Asadollahi and Tonon 2010).

Initial matedness is particularly relevant to the evolution of aperture size distributions during the early stages of shear displacement. In the following analysis, we used synthetically generated $1 \mathrm{D}$ roughness profiles to explore two matedness cases: (1) an initially "perfectly mated" fracture composed of two mirror surfaces, and (2) an initially "unmated" fracture composed of two distinct surfaces each created with the amplitude power law $X(\lambda)$ and random phase $\phi(\lambda)$ for each wavelength. Figure 4 illustrates the mean aperture size distribution obtained using 1000 realizations for unmated fractures. These results suggest that shear displacement does not affect the aperture size distribution of initially unmated fractures. By contrast, the mean and standard deviation increase with shear displacement in initially mated fractures, and reach a maximum mean aperture value when the shear displacement $\delta_{s}$ is half of the longest roughness wavelength, $\delta_{s} \sim \lambda_{\max } / 2$ (Fig. 5a).

We extended the previous analysis to include the combined effects of shear displacement (imposed first) and normal stress (Eq. 5). Figure 5a displays the mean aperture size (a)

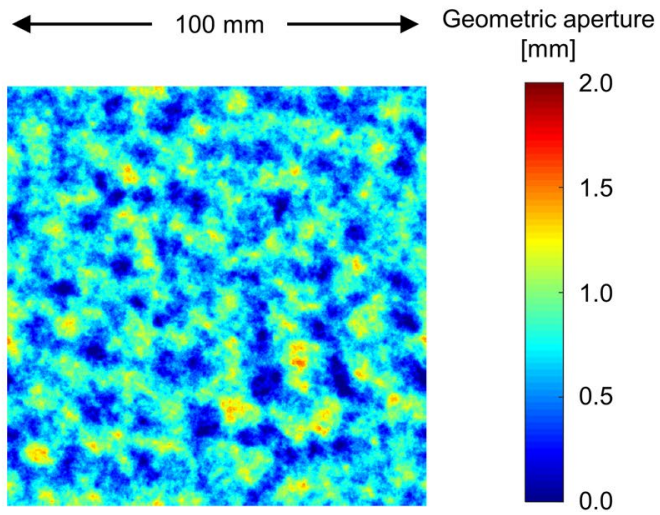

Fig. 3 Evolution of aperture size distribution during normal loading for numerically generated surfaces. A Aperture field estimated using the contact yield model at $1 \mathrm{MPa}$ for a fracture composed of two unmated synthetic surfaces. B Evolution of the aperture

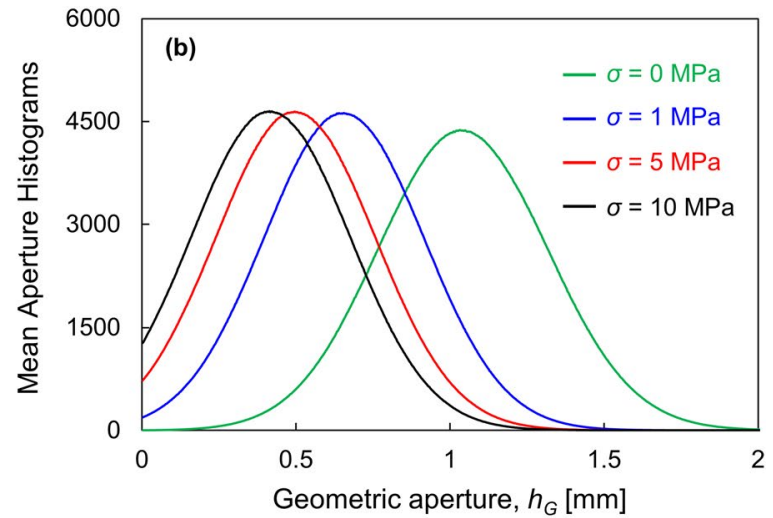

size distribution with normal stress (mean of 1000 realizations$\left.\sigma_{\text {yield }}=200 \mathrm{MPa}\right)$. 1D profiles are $100 \mathrm{~mm}$ long, and wavelengths range between $\lambda_{\text {min }}=0.02 \mathrm{~mm}$ and $\lambda_{\text {max }}=20 \mathrm{~mm}$ 


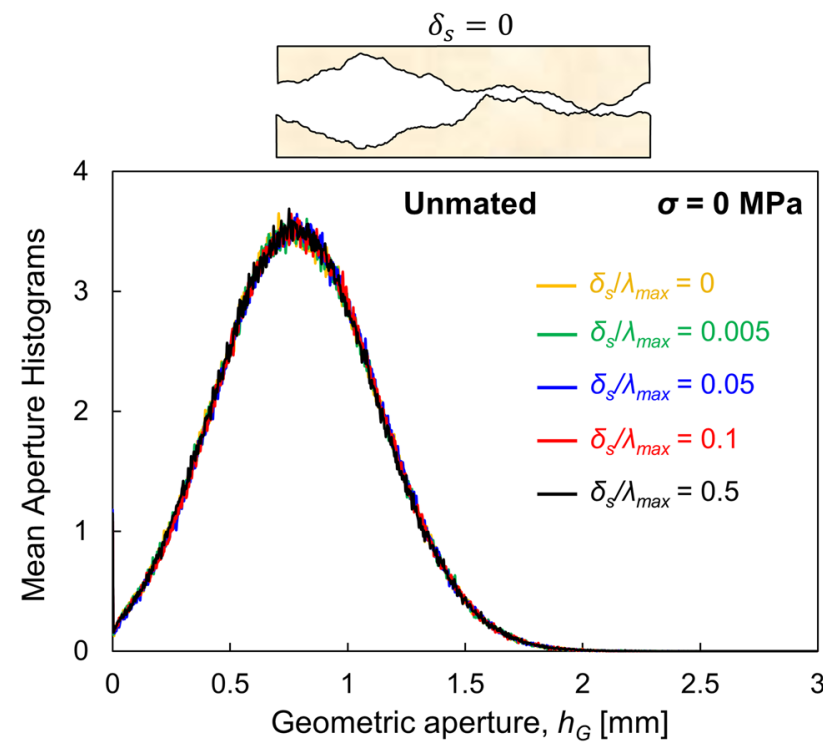

Fig. 4 Aperture size distributions during shear displacement for initially unmated fractured surfaces. Mean aperture histograms for 1000 roughness realizations. Numerically generated surfaces are $100 \mathrm{~mm}$ long and have a maximum wavelength $\lambda_{\max }=20 \mathrm{~mm}$. The shear displacement $\delta_{s}$ is normalized by $\lambda_{\max }$ shows the lateral offset. Note: the roughness profile shown has an exaggerated vertical scale for clarity

distribution obtained from 1000 realizations at normal stress $\sigma=0 \mathrm{MPa}$ for initially mated fracture surfaces after four different shear displacements. Figure $5 \mathrm{~b}$ shows aperture histograms after normal loading to $\sigma=10 \mathrm{MPa}$. The effects of normal loading and asperity yield after shear displacement on aperture size distribution are more pronounced as matedness decreases with increased shear displacement. Note that the adopted contact model does not consider asperity shear.

\section{Flow: Hydraulic Aperture}

Flow follows the path of least drag in a variable aperture field. Thus, flow trajectories deviate from linear streamlines. A fracture's "hydraulic aperture" $h_{H}$ is the equivalent aperture between two parallel flat plates that allow the same flow for the same pressure gradient assuming the cubic law (Witherspoon et al. 1980). Estimates of the hydraulic aperture are based on statistics (Table 2). Interestingly, most models anticipate that the hydraulic aperture decreases as the aperture coefficient of variation $s_{G} / \mu_{G}$ increases where $s_{G}$ is the aperture standard deviation and $\mu_{G}$ its mean. Analogous conclusions using network models for a wide range of pore size distributions can be found in Jang et al. (2011). Numerical studies, new experimental data, and data compiled from published studies are used herein to extend previous fracture flow analyses.

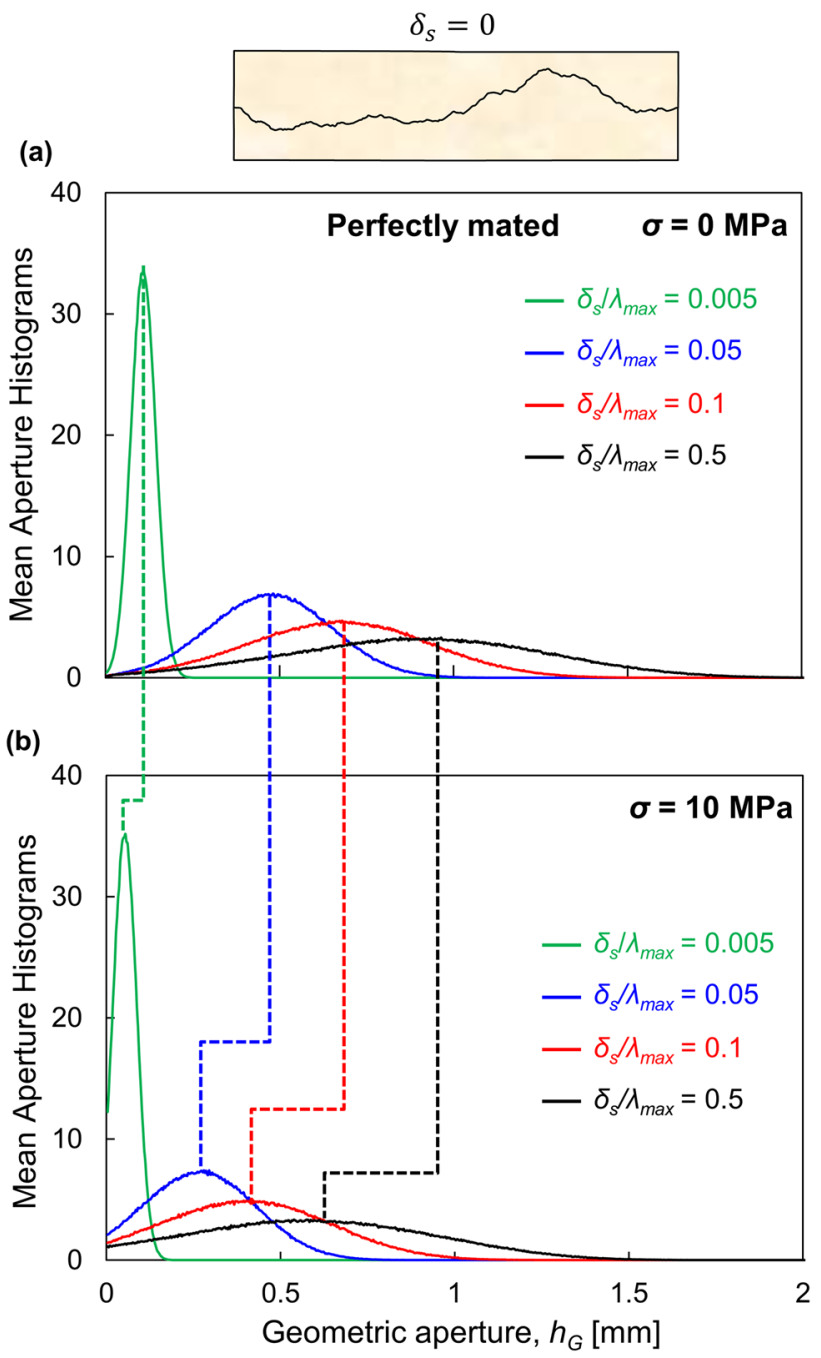

Fig. 5 Evolution of aperture size distribution during shear displacement for initially mated fractures. Mean aperture histograms for 1000 realizations. A $\sigma=0 \mathrm{MPa}$, B Normal stress $\sigma=10 \mathrm{MPa}$ imposed after shear displacement. Dashed lines relate histograms before and after normal load. Note: the roughness profile shown has an exaggerated vertical scale for clarity

\subsection{Numerical Study: Evolution of Transmissivity with Normal Stress and Shear Displacement}

We assumed the cubic law to be locally valid. Then, Stokes flow and continuity requirements result in the following expression, similar to the seepage flow equation for a heterogeneous medium (Oron and Berkowitz 1998):

$\frac{\partial}{\partial x}\left(h_{G}^{3} \frac{\partial P}{\partial x}\right)+\frac{\partial}{\partial y}\left(h_{G}^{3} \frac{\partial P}{\partial y}\right)=0$,

where $h_{G}$ is geometric aperture.

This equation assumes that (1) roughness amplitudes $X$ are much smaller than the roughness wavelength $\lambda(\lambda / X \gg 1)$, 
Table 2 Hydraulic aperture models

\begin{tabular}{ll}
\hline Model & References \\
\hline$\frac{h_{H}^{3}}{\mu_{G}^{3}}=\left(\frac{\mu_{G} / \mu m}{\mathrm{JRC}^{2.5}}\right)^{3}$ & $\begin{array}{c}\text { Barton et al. (1985); Esaki et al. } \\
(1999)\end{array}$ \\
$\frac{h_{H}^{3}}{\mu_{G}^{3}}=\frac{1}{1+A_{H}\left(\frac{2 \mu_{G}}{s_{G}}\right)^{1.5}}$ & Lomize (1951), Brown (1987) \\
$\frac{h_{H}^{3}}{\mu_{G}^{3}}=\left(1-C_{H} e^{\left.-B_{H}\left(\frac{\mu_{G}}{s_{G}}\right)\right)}\right.$ & Partir and Cheng (1978) \\
$\frac{h_{H}^{3}}{\mu_{G}^{3}}=\frac{\mu_{G}}{s_{G}} \frac{(1-c)}{(1+c)}$ & Brown (1987) \\
$\frac{h_{H}^{3}}{\mu_{G}^{3}}=(1-2 c)$ & Li et al. (2008) \\
$\frac{h_{H}^{3}}{\mu_{G}^{3}}=\left[1-1.5\left(\frac{s_{G}}{\mu_{G}}\right)^{2}\right](1-2 c)$ & $\begin{array}{c}\text { Zimmerman and Bodvarsson (1996); } \\
\text { Chen et al. (2017) }\end{array}$ \\
$\frac{h_{H}^{3}}{\mu_{G}^{3}}=\left(1+3(1-3 \alpha) S^{2}+\cdots\right)$ & $\begin{array}{c}\text { Inoue and Sugita (2003); Auradou } \\
\text { (2009) }\end{array}$ \\
$S=\frac{s_{G}}{\mu_{G}} ; \alpha=\int \frac{\theta(\kappa)}{2 \pi^{2}} \mathrm{~d} \kappa$ &
\end{tabular}

and (2) the wavelength is much greater than the aperture $\left(\lambda / h_{G} \gg 1\right)$. The power function between roughness and wavelength automatically satisfies the first assumption (Fig. 1 and Eqs. 1 and 3). The second assumption is valid taking into consideration the wavelength that controls the aperture. Note that two sinusoidal surfaces in contact create

(a)

Flow rate $Q\left[\mathrm{~m}^{3} / \mathrm{s}\right]$

$\sigma=0 \mathrm{MPa}$
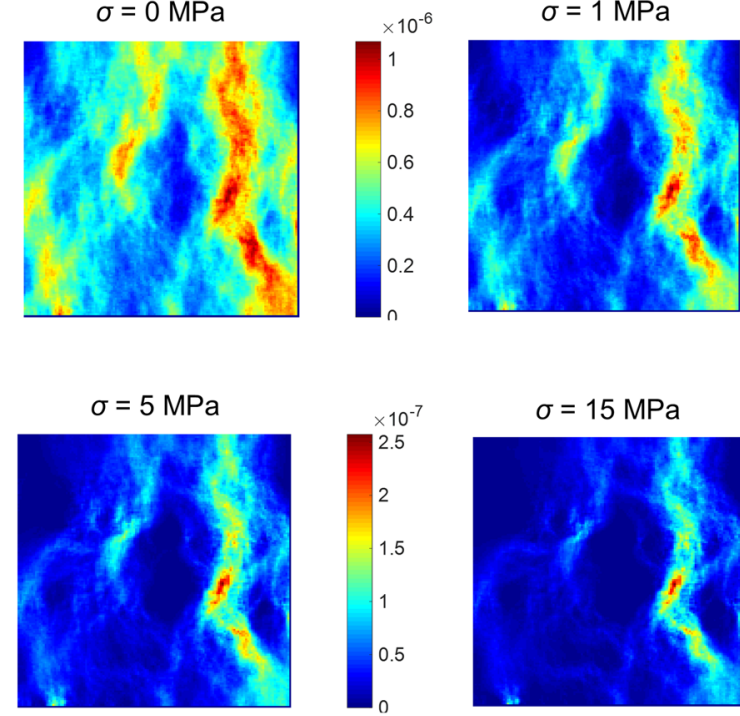

Fig. 6 Transmissivity changes due to normal load. A Estimated flow rates through an unmated fracture using the contact yield and local cubic law approximations for different normal stresses $\left(\sigma^{\prime}=0,1,5\right.$, and $15 \mathrm{MPa}-\mathrm{Eq} .5$ for an assumed yield stress of $200 \mathrm{MPa})$. B The a $h_{G}=4 X$ aperture when the shear displacement is $\lambda / 2$, i.e., a $\pi$-shift.

We solved Eq. 6 using finite differences and explored the implications of changes in geometrical aperture on flow due to changes in effective normal stress. Numerical results in Fig. 6 show the decrease in fracture transmissivity as the effective normal stress increases for different yield stress values $\sigma_{\text {yield }}$. Besides the reduction in aperture, the increase in contact area leaves a smaller available fracture cross section for flow. Figure 6 a shows flow rate magnitudes at different stress levels for a synthetic unmated fracture: flow trajectories redistribute and flow channeling becomes more pronounced at later stages of loading because larger aperture channels remain open and control flow. In fact, the fracture area responsible for $90 \%$ of the flow reduces during loading (Fig. 6b).

Transmissivity data gathered in the field suggest that shear dilation in critically stressed natural fractures enhances fluid flow, predominantly in crystalline rocks (Barton et al. 1995). Shear displacement induces aperture anisotropy. Contact points increase in the direction of shear, detach transversely to the shear direction, and therefore, aperture ridges emerge on the fracture aperture field (Gentier et al. 1997; Yeo et al. 1998; Auradou et al. 2005; Matsuki et al. 2010). Consider a synthetic initially mated rough fracture (i.e., zero aperture) subjected to shear displacement in the $y$-direction (Fig. 7a). The geometric aperture field at different levels of shear displacement in Fig. 7a displays a clear alignment of

\section{(b)}

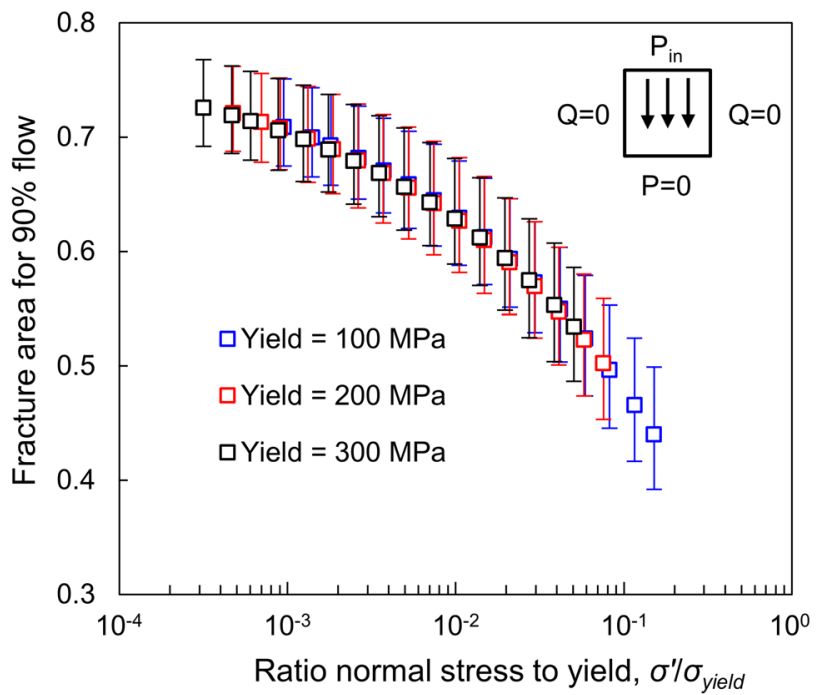

fraction of the fracture area that carries $90 \%$ of the total flow for 1000 realizations. Vertical bars indicate the 25 th and 75 th percentiles. The inset shows the assumed pressure gradient (top to bottom) and the noflow side boundaries 
(a) Geometric aperture $h_{G}[\mathrm{~m}]$

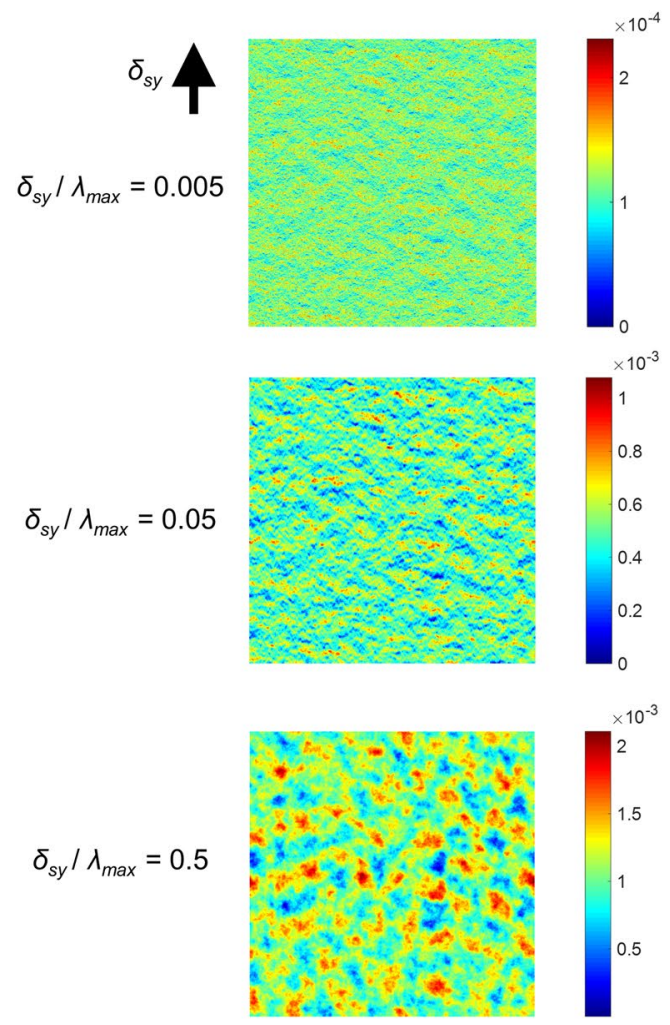

Fig. 7 Transmissivity changes during shear displacement. A Geometric apertures for different levels of shear displacement at $0 \mathrm{MPa}$ of normal stress and initially perfectly mated fracture. B Evolution in

apertures transverse to the shear direction at early stages of shear as discussed above. The ensuing transmissivity anisotropy is most pronounced soon after shear displacements starts $\delta_{s} / \lambda_{\max }<0.1$, and gradually decreases toward isotropic conditions at large shear displacements when all surface correlations are lost (Fig. 7b). Datapoints in Fig. 7b are averages of 1000 realizations, and error bars show that the anisotropy variability increases with shear displacement due to the higher probability of dominant flow paths.

\subsection{Experimental Study: Torsional Ring Shear Device}

Numerical results highlight profound differences in the evolution of geometric aperture and flow during normal loading and shear displacement, and the impact on natural fracture surface roughness and matedness. A focused experimental study complements this numerical study.

We designed and manufactured a torsional ring shear device to subject a pre-fractured cylindrical specimen to normal stresses up to $30 \mathrm{MPa}$, to independently apply a torsional shear displacement, and to impose radial flow through (b)

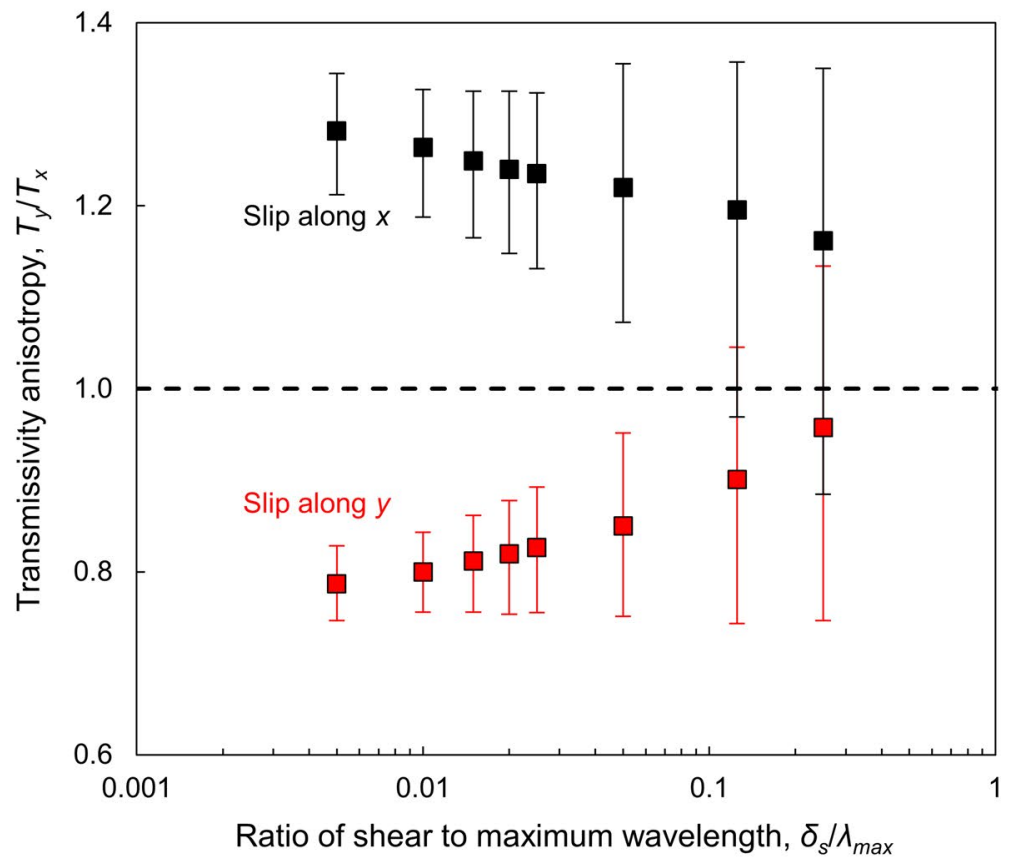

transmissivity anisotropy for shear displacement along $x$ and $y$ directions (1000 realizations). Vertical bars indicate the 25th and 75th percentiles

the annular fracture plane (Fig. 8). This device benefits from accurate normal stress and shear displacement control, imposes precise flow boundaries without the need for jacketed specimens, maintains a constant nominal fracture area throughout the test, and reduces stress localization (for comparison, see: linear shear in Esaki et al. 1999; biaxial tests in Makurat et al. 1990; triaxial configuration in Teufel 1987; and torsional shear in Olsson 1992).

The reaction load frame houses a pressure-controlled hydraulic jack to impose the vertical load, and two horizontal screw positioners to exert the torsional moment via diametrically opposite lever arms. Fluid is injected into the fracture plane through a small central hole drilled into the specimen's lower half. The instrumentation includes a LVDT to record the normal displacement, strain-gages mounted on the lever arms to measure torque, and two pressure transducers to monitor the fluid pressure at low and high pressure ranges.

The limestone specimen preparation method involved five steps: (1) core two $56 \mathrm{~mm}$ diameter cylindrical plugs, (2) modify the fracture surface by either sandblasting or polishing, (3) cut a cross-shaped groove on the other side 
(a)

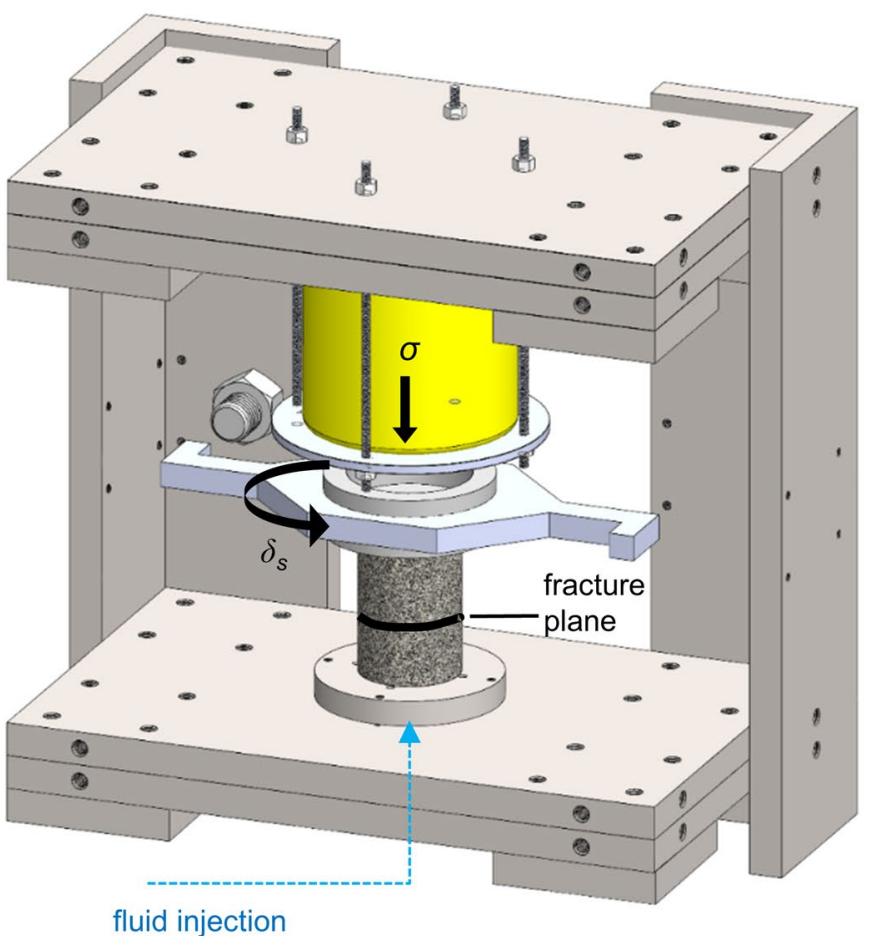

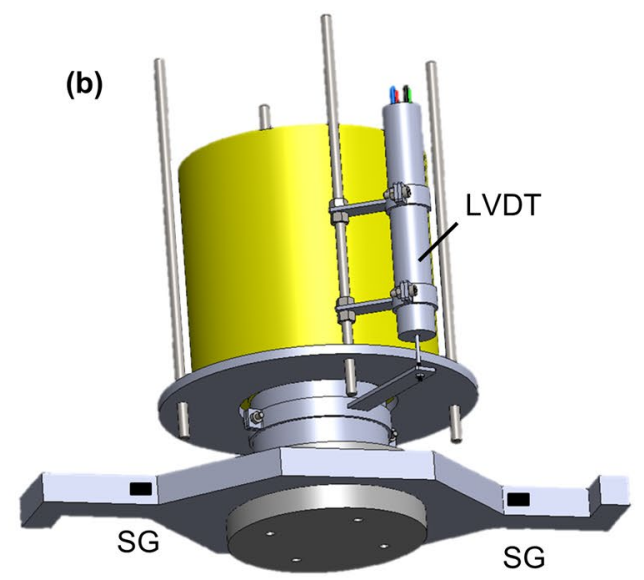

(c)

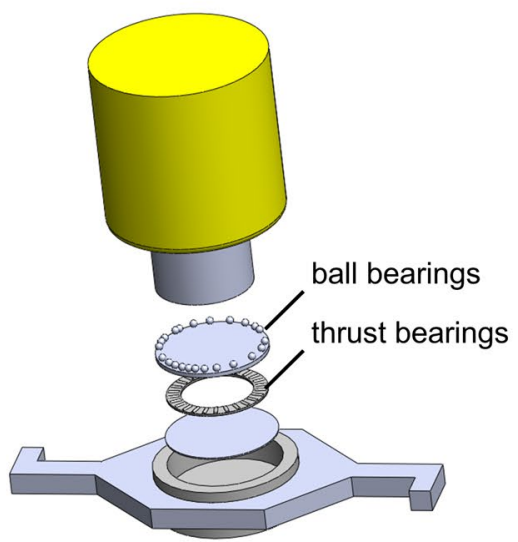

Fig. 8 Torsional shear device to assess fracture transmissivity as a function of normal stress and shear displacement. A Reaction frame, hydraulic cylinder for vertical load, lever arm and specimen. B Instru-

of each plug to accommodate the torque transmission cap, (4) drill the central hole and chamber in one of the two plugs for fluid injection (hole diameter $=3.5 \mathrm{~mm}$, chamber diameter $=18 \mathrm{~mm}$ ), and (5) attach with epoxy the two steel caps onto the rock cylinders. For natural fractures, we cored across the fracture and implemented steps 3,4 , and 5 detailed above.

Figure 9 shows typical experimental results where transmissivity decreases with effective normal stress. The smooth and rough limestone specimens start with distinct geometrical aperture fields, yet their transmissivities converge as the effective normal stress exceeds $\sim 1 \mathrm{MPa}$ (Fig. 9a). On the other hand, the high roughness variability in a natural fracture plane, with longer asperity wavelength, localizes contact yield at few asperities; there is a reduced effect on the governing large flow channels and transmissivity exhibits lower sensitivity to normal stress (Fig. 9b). A set of five tests conducted with limestone plugs confirmed these observations.

Results in Fig. 7 call for the analysis of hydro-mechanical boundary conditions in experimental and numerical studies, mentation: LVDT to monitor the fracture normal displacement and strain gages SG to measure the applied torque. $\mathbf{C}$ Ball bearings in the annular space between the cap and the plunger preserve the coaxility

relative to field conditions. For example, radial flow in our ring shear device is normal to the shear direction; on the other hand, most numerical and experimental studies impose flow collinear with shear. In addition, radial flow and torsional shear imply a radial gradient in fluid velocity and shear displacement; we minimize radial effects by limiting the ratio between the external specimen diameter and the internal chamber size $(56 \mathrm{~mm} / 18 \mathrm{~mm}$ in this study).

\subsection{Transmissivity Models: Normal Stress and Shear Displacement}

We compiled a database of fracture transmissivity evolution with normal stress and shear displacement for various rock types. Data sources cover a wide range of measurement techniques (e.g., linear, biaxial, and torsional shear) and boundary conditions (i.e., linear and radial flow). This database, which includes published results and our experimental results, allow us to advance new physics-inspired yet data-driven transmissivity models. 


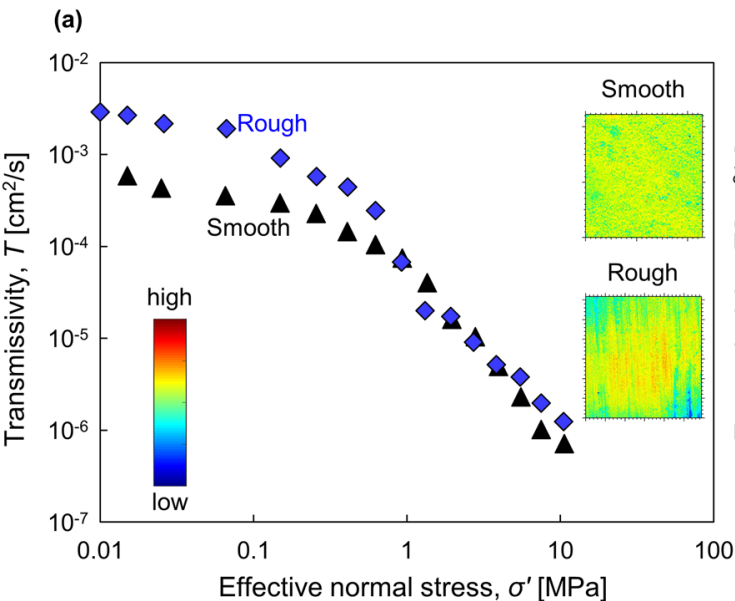

Fig. 9 Evolution of transmissivity with normal stress-Experimental data. A Limestone specimen with two different surface roughness. Insets correspond to roughness scans for the smooth $(2.3 \times 2.3 \mathrm{~mm})$

\subsubsection{Normal Stress}

Earlier fracture transmissivity models as a function of normal stress recognized non-linear contact behavior and asperity yield, flow channeling, and the influence of fracture roughness (e.g., Pyrak-Nolte and Nolte 2016). These phenomenological models involve power, logarithmic, or exponential decay functions for transmissivity as a function of normal stress. However, these models fail to capture the asymptotic behavior of fracture transmissivity $T$ $\left(\mathrm{cm}^{2} / \mathrm{s}\right)$ at very low effective normal stress $\left(T_{\sigma 0}\right.$ as $\left.\sigma^{\prime} \rightarrow 0\right)$ and very high effective normal stress $\left(T_{\sigma \infty}\right.$ as $\left.\sigma^{\prime} \rightarrow \infty\right)$ and may be unreliable for general applications.

We modified a selection of published models to satisfy asymptotic behavior so that transmissivity reaches prescribed values when the effective stress approaches zero or infinity (see Table 3). Then, we fitted trends in the database with the various models. The following power-law expression provides the best fit for all cases analyzed in this study:

$\frac{T\left(\sigma^{\prime}\right)-T_{\sigma_{\infty}}}{T_{\sigma_{0}}-T_{\sigma_{\infty}}}=\left(\frac{\sigma^{\prime}+\sigma_{c}}{\sigma_{c}}\right)^{-\gamma}$.

This four parameter model indicates that transmissivity $T\left(\sigma^{\prime}\right)$ at a given effective normal stress $\sigma^{\prime}$ normalized by the asymptotic values $T_{\sigma 0}$ and $T_{\sigma \infty}$ is a function of the normalized effective normal stress with respect to the characteristic stress $\sigma_{c}$, where the $\gamma$-exponent captures the transmissivity stress-sensitivity (Fig. 10). Note that the normalized transmissivity is $2^{-\gamma}$ when the normal stress is equal to the characteristic stress $\sigma^{\prime}=\sigma_{c}$. Complementary numerical simulations not shown here indicate that (1) fracture roughness and

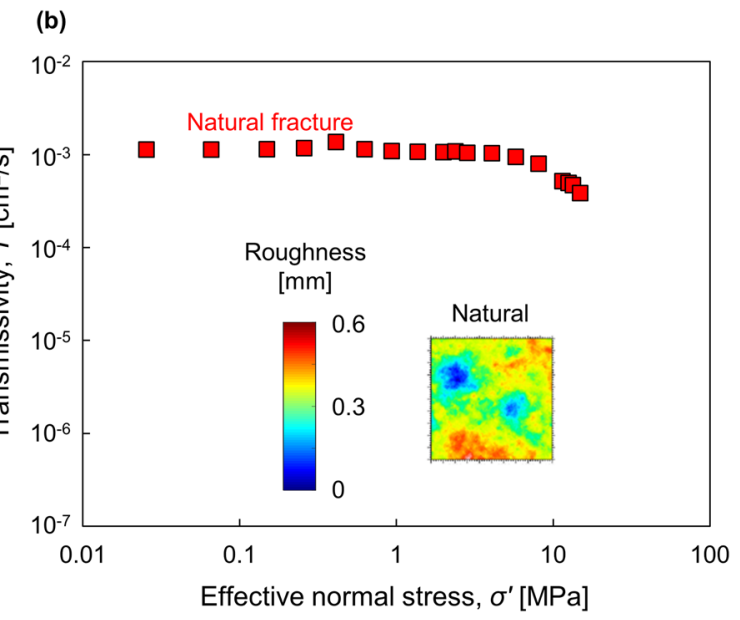

and rough $(6 \times 6 \mathrm{~mm})$ fracture surfaces. Color bar values range from 0 to $0.06 \mathrm{~mm}$ and from 0 to $0.1 \mathrm{~mm}$, respectively. B Natural specimen. The inset corresponds to the roughness of a $10 \times 10 \mathrm{~mm}$ specimen

matedness control the transmissivity asymptotes $T_{\sigma 0}$ and $T_{\sigma \infty}$, and (2) $\sigma_{c}$ is a function of the rock yield stress $\sigma_{\text {yield. }}$.

Figure 10 illustrates data clustering according to rock type: fractures in sandstones are more sensitive to stress $(\gamma=3$-to-20), whereas the transmissivity in igneous and metamorphic rocks exhibits a lower stress-sensitivity $(\gamma=0.4-$ to-2). The exponent $\gamma$ for limestone specimens tested in this study ranges from $\gamma=3$-to- 8 .

\subsubsection{Shear Displacement}

Previous empirical models for transmissivity during shear displacement relate shear dilation to the joint roughness coefficient JRC or an empirical fitting factor (Table 4). Some models recognize cataclasis during shear displacement, but are complex and require shear stress information (Plesha 1987; Nguyen and Selvadurai 1998). Furthermore, available empirical and theoretical models are asymptotically incorrect, thus, unreliable for general applications.

We adopted the following logistic function with a distinct S-shaped trend in log-log scale to capture the evolution of the normalized transmissivity during shear displacement:

$\frac{T\left(\delta_{s}\right)-T_{\delta_{0}}}{T_{\delta_{\infty}}-T_{\delta_{0}}}=\frac{e^{\left(\frac{1}{1+e^{\eta\left(1-\delta_{s} / \delta_{s c}\right)}}-1\right)}-T_{c}}{1-T_{c}} \quad$ where $T_{c}=e^{\left(\frac{1}{1+e^{\eta}}-1\right)}$.

The four parameters model capture: the sensitivity of the fracture transmissivity to shear displacement in the $\eta$-exponent, the displacement at maximum dilatancy or contractive rate in the characteristic shear displacement $\delta_{s c}$, and the transmissivity asymptotes $T_{\delta 0}$ as $\delta_{s} \rightarrow 0$ and $T_{\delta \infty}$ as $\delta_{s} \rightarrow \infty$. This model can accommodate data that exhibits 
Table 3 Fracture transmissivity models as a function of effective normal stress. Notes models are modified to satisfy asymptotic behavior

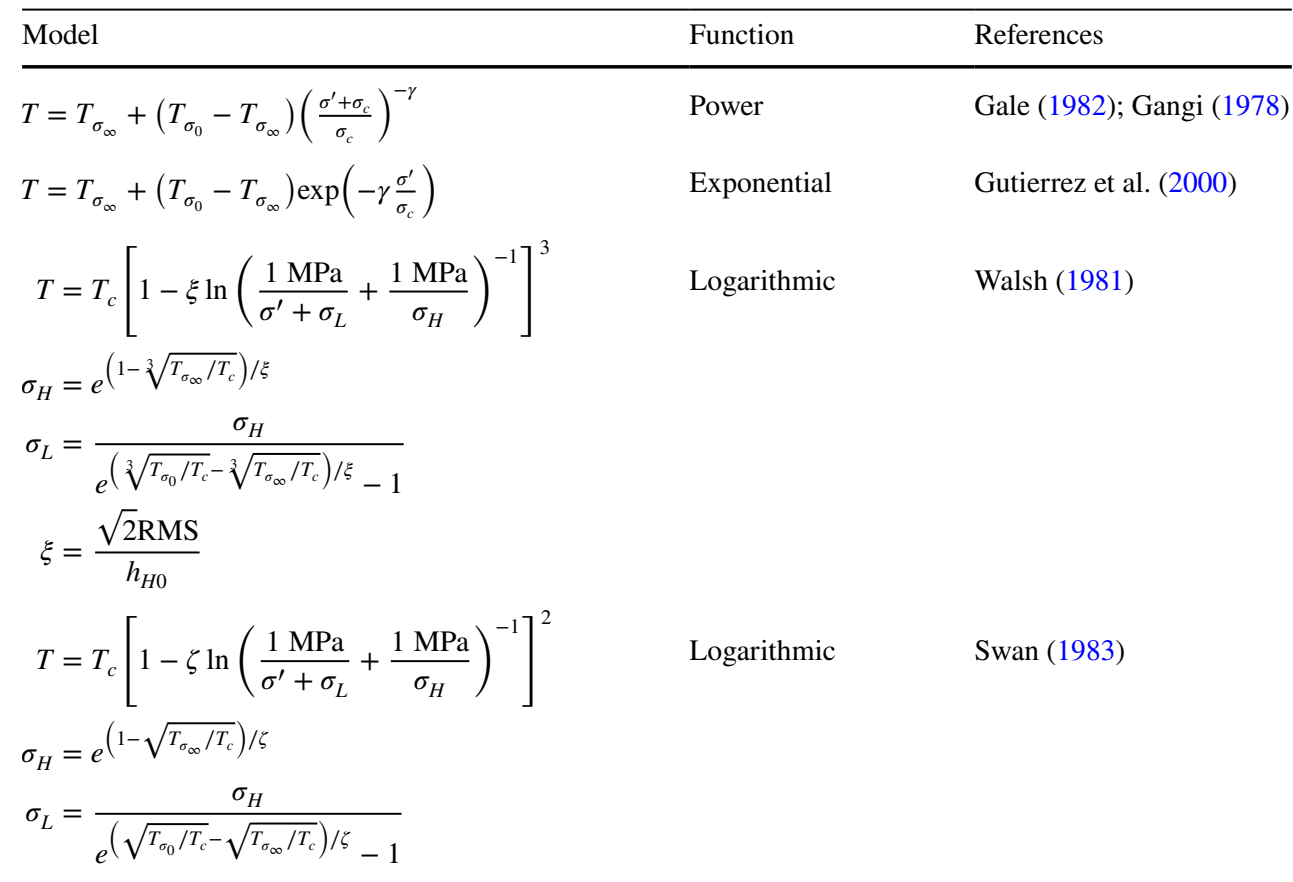

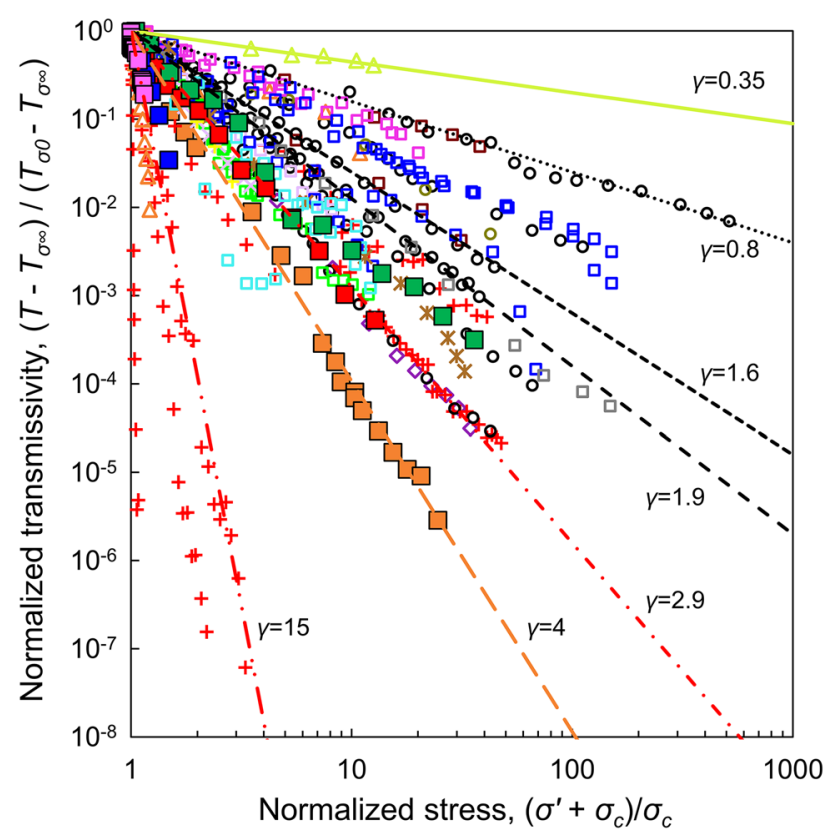

Fig. 10 Transmissivity as a function of normal stress-Experimental data and fitted power model (Eq. 7). Transmissivity normalized with respect to the transmissivity at zero and infinite normal stress $T_{\sigma 0}$ and $T_{\sigma \infty}$. Empty markers: published data. Filled markers: experimental data for limestone specimens (this study). Rock type: square-granites, diamond-granodiorites, cross-sandstones, 4 point star-marbles, triangle-shales, circle-gneiss, and 6 point star-amphibolites. Data sources: Witherspoon et al. (1980) (gray); Gale (1982) (black); Raven and Gale (1985) (blue); Brown and Kranz (1986) (purple); Makurat (1990) (olive); Wilbur and Amadei (1990) (yellow); Boulon et al. (1993) (maroon); Durham (1997) (brown); Indraratna et al. (1999) (green); Gutierrez et al. (2000) (orange); Pyrak-Nolte and Morris (2000) (magenta); Lee and Cho (2002) (lavender); Watanabe et al. (2008) (cyan); Cuss et al. (2011) (lime); Chen et al. (2017) (red)
Table 4 Fracture transmissivity models as a function of shear displacement

\begin{tabular}{|c|c|}
\hline Model & References \\
\hline$T=\frac{\rho g}{12 \mu}\left(\mu_{G} / \mu \mathrm{m}\right)^{3 / 2} \mathrm{JRC}_{\mathrm{mob}}^{3}$ & $\begin{array}{l}\text { Olsson and Barton } \\
\text { (2001) }\end{array}$ \\
\hline $\begin{array}{l}T=\frac{\rho g}{12 \mu}\left(h_{H 0}+f \cdot h\right)^{3} \\
\quad f=f_{o} \exp \left(-\int_{0}^{W^{p}} c_{f} \mathrm{~d} W^{p}\right)\end{array}$ & $\begin{array}{l}\text { Plesha (1987); Nguyen } \\
\text { and Selvadurai (1998) }\end{array}$ \\
\hline $\begin{array}{c}T=\frac{\rho g}{12 \mu}\left(\frac{A_{s}}{1+9 \frac{\sigma_{n}^{\prime}}{B_{s}}} h_{H 0}\right) \text { where } \\
A_{s}= \begin{cases}1 & \text { before shear } \\
>1 & \text { after shear }\end{cases} \end{array}$ & Tezuka et al. (2005) \\
\hline
\end{tabular}

either monotonic dilation or contraction during shear; in fact, Zhou et al. (2018) proposed a similar mathematical expression for dilation.

Figure 11 presents normalized transmissivity data plotted against the normalized shear displacement $\delta_{s} / \delta_{s c}$ for studies reported in the literature and new data gathered in this study. The limited clustering by rock type suggests that changes in aperture are most sensitive to initial fracture roughness and matedness. In fact, complementary numerical simulations with synthetic fractures not shown in this manuscript demonstrate that roughness, matedness, and normal stress determine the transmissivity asymptotes $T_{\delta 0}$ and $T_{\delta \infty}$, and the characteristic shear displacement $\delta_{s c}$. The $\eta$-exponent reflects the dilative tendency which is a function of surface roughness and initial matedness for a given normal stress. 


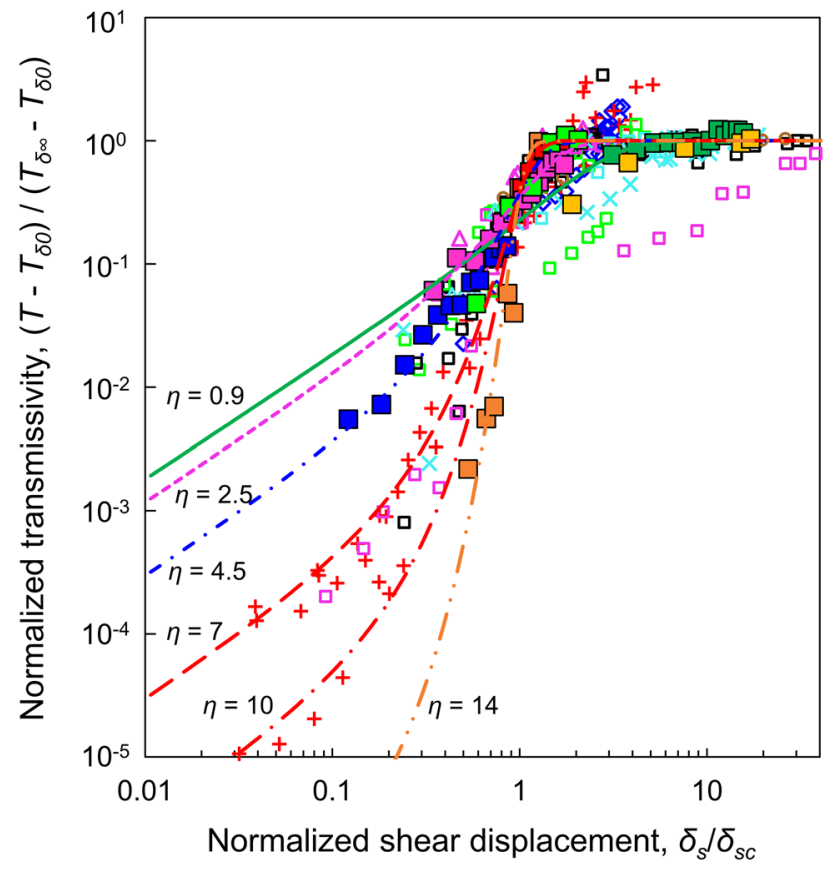

Fig. 11 Transmissivity as a function of shear displacement-Experimental data and fitted logistic model (Eq. 8). Transmissivity normalized with respect to the transmissivity at zero and infinite shear displacement $T_{\delta 0}$ and $T_{\delta \infty}$. Empty markers: published data. Filled markers: experimental data for limestone specimens (this study). Rock type: square-granites, diamond-plaster, cross-mortar, 4 point star-sandstone, triangle-marbles, welded tuff-gneiss, and 6 point starchalk. Data sources: Makurat 1990 (cyan); Esaki et al. 1991 (black); Olsson 1992 (brown); Ahola et al. 1996 (green); Gentier et al. 1996 (gray); Cheon et al. 2002 (magenta); Li et al. 2008 (blue); Nishiyama et al. 2014 (red)

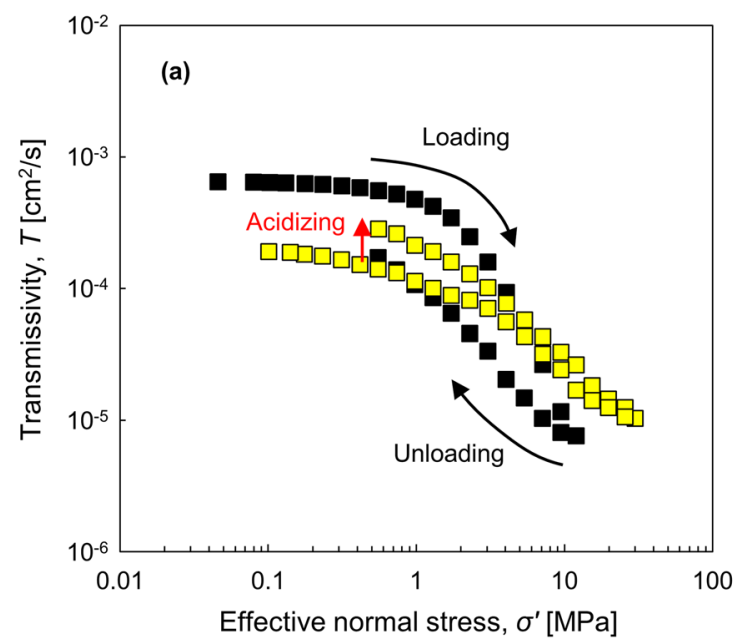

Fig. 12 Fracture transmissivity changes due to dissolution. Limestone subjected to the injection of $\mathrm{HCl}$ solution-pH 2 at $1 \mathrm{~cm}^{3} / \mathrm{min}$. (A) Fracture transmissivity versus effective normal stress and (B) normal displacement versus effective normal stress before (black) and after

\subsection{Hydro-Chemo-Mechanical Coupling: Dissolution}

Carbonate rocks exhibit high solubility and high reaction rates (Plummer et al. 1978). Consequently, mineral dissolution, and precipitation play a significant role in the evolution of both geometric and hydraulic apertures. The Damkhöler number compares reaction kinetics and advective transport, while the transverse Peclet number contrasts longitudinal advective transport to diffusive transport across the fracture (Fredd and Fogler 1998; Golfier et al. 2002). These two dimensionless ratios help anticipate the type of transport regime: homogeneous dissolution, near-inlet dissolution, or channeling (Elkhoury et al. 2013; Deng et al. 2015).

Mineral dissolution impacts the aperture evolution for a given normal stresses. We explored the evolution of fracture transmissivity due to reactive fluid flow across a limestone specimen with an initially polished fracture surface using our annular fracture flow device. Figure 12 presents the fracture transmissivity and normal displacement data during loading and unloading before acid treatment. The initial transmissivity-stress trends obtained with water follow a typical compaction behavior, where transmissivity decreases as effective normal stress increases. We injected $5 \mathrm{~cm}^{3}$ of a $\mathrm{pH}=2 \mathrm{HCl}$-solution at $1 \mathrm{~cm}^{3} /$ min under constant normal stress $\sigma_{z}=0.55 \mathrm{MPa}$. For a diffusion coefficient $D=2 \times 10^{-9} \mathrm{~m}^{2} / \mathrm{s}$, mean fracture aperture $h_{H}=25 \mu \mathrm{m}$, and kinetic rate $k=3.2 \mathrm{~s}^{-1}$, the Damkhöler and Peclet numbers are $\mathrm{Da}=9.1$ and $\mathrm{Pe}=2.7 \times 10^{-2}$ respectively (see Kim and Santamarina 2016 for detailed Da and Pe definitions). These high Damkhöler and Peclet numbers imply fast reaction and seepage which cause near-inlet dissolution. Then, we

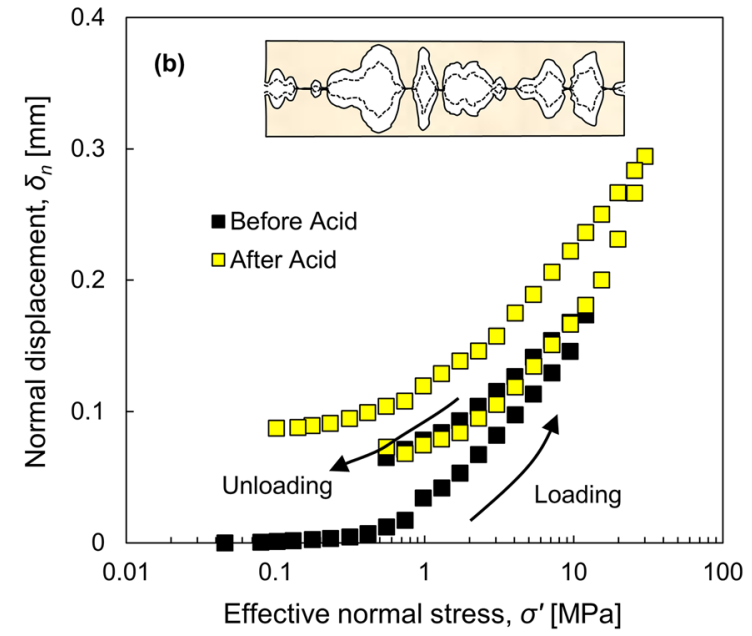

(yellow) acidizing treatment. The inset sketch illustrates the hypothesized aperture evolution following dissolution (dashed lines: surface before acidization) 
measured transmissivity and normal displacement during a second loading-unloading cycle. There is a marked increment in fracture transmissivity during acid injection and insignificant changes in normal displacement. Thereafter, gains in transmissivity remain during loading even at high stress. This observation suggests the formation of dissolution channels during the acid treatment while the true contact area between fracture planes remains unaltered (see inset in Fig. 12).

\section{Conclusions}

Fluid flow in fractured rock masses is a common phenomenon in natural and engineered systems, from infrastructure applications to resource recovery and $\mathrm{CO}_{2}$ geological storage. Fracture transmissivity along fractures defines the prevalent flow paths and controls all forms of hydro-thermochemo-bio-mechanically coupled processes. This study combined data compilation, new experimental data, and numerical studies to advance the understanding of fracture roughness, aperture, and transmissivity.

The fracture roughness reflects mineralogy and fabric at small scales compounded by kinematics at large scales. The power spectral density captures the inherent interplay between surface roughness amplitude and wavelength: $\left(X_{u} / X_{v}\right)=\left(\lambda_{u} / \lambda_{v}\right)^{\beta / 2}$ where $\beta$ ranges from $\beta=1.9$ to 3 . When plotted against wavelength, roughness power spectral density data cluster along a single trend for more than eight orders of magnitude in roughness wavelength with a global $\beta \approx 2.8$. Deviations from this trend at large wavelengths in artificially roughened specimens suggest non-natural smoothness and highlight experimental limitations to study large scale fracture processes. Nevertheless, the fractal nature of surface roughness provides a convenient framework for analytical and numerical studies.

Specimen size limitations and fractal characteristics limit physical experiments. Statistical numerical experimentation appear as a valuable approach to study fracture transmissivity. Our normal contact and kinematically based shear models provide first-order insight on fracture deformation. The power function between fracture roughness and wavelength automatically guarantees the validity of the simplified Navier-Stokes model (i.e., local cubic law).

Surface roughness and matedness define fracture aperture and its evolution during normal loading and shear displacement. Normal stress increments cause contact yield, fracture closure, and changes in the fracture void space. The closure of small local apertures increases the relative contribution of larger interconnected voids and promotes flow channeling. Rougher unmated surfaces preserve channels during loading, and transmissivity exhibits lower stress sensitivity. An asymptotically correct power function accurately captures the evolution of transmissivity with normal stress. Model parameters reflect initial roughness, matedness, and mineralogy.

The shear displacement of unmated fractures results in statistically identical aperture fields. By contrast, shear displacement increases both the aperture mean and standard deviation in initially mated fractures; in this case, contacts align along ridges transversely to the shear direction and lead to anisotropy in transmissivity during early stages of shear displacement. However, anisotropy decreases as the shear displacement increases (relative to the largest wavelength present in the fracture). A logistic function represents transmissivity changes with shear displacement. The fracture roughness, initial matedness, and normal stress relative to yield determine the transmissivity asymptotes.

Reactive flow modifies the void space. The impact of dissolution on fracture transmissivity depends on the rates of reaction, diffusion, and advection. In high advective regimes, transmissivity increases due to positive advective-reactive feedback and channeled erosion, even at minimal normal fracture displacement.

Acknowledgements Support for this research was provided by the KAUST Endowment at King Abdullah University of Science and Technology with additional funding by Saudi ARAMCO. G. E. Abelskamp edited the manuscript. M. Sanmurjana contributed to the design of the torsional ring shear device.

Code Availability Not applicable.

\section{Declarations}

Conflict of Interest The authors declare that they have no conflict of interest.

Availability of Data Not applicable.

Open Access This article is licensed under a Creative Commons Attribution 4.0 International License, which permits use, sharing, adaptation, distribution and reproduction in any medium or format, as long as you give appropriate credit to the original author(s) and the source, provide a link to the Creative Commons licence, and indicate if changes were made. The images or other third party material in this article are included in the article's Creative Commons licence, unless indicated otherwise in a credit line to the material. If material is not included in the article's Creative Commons licence and your intended use is not permitted by statutory regulation or exceeds the permitted use, you will need to obtain permission directly from the copyright holder. To view a copy of this licence, visit http://creativecommons.org/licenses/by/4.0/.

\section{References}

Ahola MP, Mohanty S, Makurat A (1996) Coupled mechanical shear and hydraulic flow behavior of natural rock joints. In: Stephansson O, Jing L, Tsang CF (eds) Developments in geotechnical engineering: coupled thermo-hydro-mechanical processes of 
fractured media, vol 79. Elsevier, Amsterdam, pp 393-423. https://doi.org/10.1016/S0165-1250(96)80034-4

Al-Fahmi MM, Ozkaya SI, Cartwright JA (2018) New insights on fracture roughness and wall mismatch in carbonate reservoir rocks. Geosphere 14(4):1851-1859. https://doi.org/10.1130/ges01612.1

Asadollahi P, Tonon F (2010) Constitutive model for rock fractures: revisiting Barton's empirical model. Eng Geol 113:11-32. https://doi.org/10.1016/j.enggeo.2010.01.007

Auradou H (2009) Influence of wall roughness on the geometrical, mechanical and transport properties of single fractures. J Phys D Appl Phys. https://doi.org/10.1088/0022-3727/42/21/214015

Auradou H, Drazer G, Hulin JP, Koplik J (2005) Permeability anisotropy induced by the shear displacement of rough fracture walls. Water Resour Res. https://doi.org/10.1029/2005WR003938

Aydin A (2000) Fractures, faults, and hydrocarbon entrapment, migration and flow. Mar Pet Geol 17(7):797-814. https://doi. org/10.1016/S0264-8172(00)00020-9

Barr DR, Sherrill ET (1999) Mean and variance of truncated normal distributions. Am Stat 53(4):357-361. https://doi.org/10.2307/ 2686057

Barton N (1973) Review of a new shear-strength criterion for rock joints. Eng Geol 7(4):287-332. https://doi.org/10.1016/00137952(73)90013-6

Barton N, Bandis S, Bakhtar K (1985) Strength, deformation and conductivity coupling of rock joints. Int J Rock Mech Min Sci Geomech Abstr 22(3):121-140. https://doi.org/10.1016/01489062(85)93227-9

Barton CA, Zoback MD, Moos D (1995) Fluid flow along potentially active faults in crystalline rock. Geology 23(8):683686. https://doi.org/10.1130/0091-7613(1995)023\%3c0683: FFAPAF\%3e2.3.CO;2

Beer AJ, Stead D, Coggan JS (2002) Estimation of the joint roughness coefficient (JRC) by visual comparison. Rock Mech Rock Eng 35(1):65-74. https://doi.org/10.1007/s006030200009

Berkowitz B (2002) Characterizing flow and transport in fractured geological media: a review. Adv Water Resour 25(8):861-884. https://doi.org/10.1016/S0309-1708(02)00042-8

Bertels SP, DiCarlo DA, Blunt MJ (2001) Measurement of aperture distribution, capillary pressure, relative permeability, and in situ saturation in a rock fracture using computed tomography scanning. Water Resour Res 37(3):649-662. https://doi.org/10. 1029/2000wr900316

Boulon MJ, Selvadurai APS, Benjelloun H, Feuga B (1993) Influence of rock joint degradation on hydraulic conductivity. Int J Rock Mech Min Sci Geomech Abstr 30(7):1311-1317. https://doi. org/10.1016/0148-9062(93)90115-T

Briggs S, Karney BW, Sleep BE (2017) Numerical modeling of the effects of roughness on flow and eddy formation in fractures. J Rock Mech Geotech Eng 9(1):105-115. https://doi.org/10. 1016/j.jrmge.2016.08.004

Brodsky EE, Kirkpatrick JD, Candela T (2016) Constraints from fault roughness on the scale-dependent strength of rocks. Geology 44(1):19-22. https://doi.org/10.1130/g37206.1

Brown SR (1987) Fluid flow through rock joints: the effect of surface roughness. J Geophys Res Solid Earth 92(B2):1337-1347. https://doi.org/10.1029/JB092iB02p01337

Brown SR (1995) Simple mathematical model of a rough fracture. J Geophys Res 100(B4):5941-5952. https://doi.org/10.1029/ 94JB03262

Brown SR, Kranz RL (1986) Correlation between the surfaces of natural rock joints. Geophys Res Lett 13(13):1430-1433. https:// doi.org/10.1029/GL013i013p01430

Brown SR, Scholz CH (1986) Closure of Rock Joints. J Geophys Res 91(B5):4939-4948. https://doi.org/10.1029/JB091iB05p04939
Candela T, Renard F, Klinger Y, Mair K, Schmittbuhl J, Brodsky EE (2012) Roughness of fault surfaces over nine decades of length scales. J Geophys Res. https://doi.org/10.1029/2011JB009041

Chen G, Spetzler H (1993) Topographic characteristics of laboratory induced shear fractures. PAGEOPH 140(1):123-135. https:// doi.org/10.1007/bf00876874

Chen Y, Liang W, Lian H, Yang J, Nguyen VP (2017) Experimental study on the effect of fracture geometric characteristics on the permeability in deformable rough-walled fractures. Int J Rock Mech Min Sci 98:121-140. https://doi.org/10.1016/j.ijrmms. 2017.07.003

Cheon D, Lee H, Jeon S, Lee C (2001) A study of hydromechanical behaviors of rock joints using torsional shearing system. In: Proceedings of the ISRM 2nd Asian Rock Mechanics Symposium, Beijing, China, pp 185-188. ISRM-ARMS2-2001-039

Cuss RJ, Milodowski A, Harrington JF (2011) Fracture transmissivity as a function of normal and shear stress: first results in Opalinus Clay. Phys Chem Earth Parts a/b/c 36(17-18):1960-1971. https:// doi.org/10.1016/j.pce.2011.07.080

Deng H, Fitts JP, Crandall D, McIntyre D, Peters CA (2015) Alterations of fractures in carbonate rocks by $\mathrm{CO} 2$-acidified brines. Environ Sci Technol 49(16):10226-10234. https://doi.org/10.1021/acs. est.5b01980

Dijk P, Berkowitz B, Bendel P (1999) Investigation of flow in watersaturated rock fractures using nuclear magnetic resonance imaging (NMRI). Water Resour Res 35(2):347-360. https://doi.org/ 10.1029/1998wr900044

Durham WB (1997) Laboratory observations of the hydraulic behavior of a permeable fracture from $3800 \mathrm{~m}$ depth in the KTB pilot hole. J Geophys Res Solid Earth 102(B8):18405-18416. https://doi. org/10.1029/96jb02813

Elkhoury JE, Ameli P, Detwiler RL (2013) Dissolution and deformation in fractured carbonates caused by flow of $\mathrm{CO} 2$-rich brine under reservoir conditions. Int J Greenh Gas Control. https://doi. org/10.1016/j.ijggc.2013.02.023

Esaki T, Du S, Mitani Y, Ikusada K, Jing L (1999) Development of a shear-flow test apparatus and determination of coupled properties for a single rock joint. Int J Rock Mech Min Sci 36(5):641-650. https://doi.org/10.1016/S0148-9062(99)00044-3

Fredd CN, Fogler HS (1998) Influence of transport and reaction on wormhole formation in porous media. AIChE J 44(9):19331949. https://doi.org/10.1002/aic.690440902

Gale JE (1982) The effects of fracture type (induced versus natural) on the stress-fracture closure-fracture permeability relationships. In: Proceedings of the ARMA 23rd U.S. Symposium on Rock Mechanics, Berkeley, California, ARMA-82-290

Gale JE (1987) Comparison of coupled fracture deformation and fluid flow models with direct measurements of fracture pore structure and stress-flow properties. Proceedings of the ARMA 28th U.S. Symposium on Rock Mechanics, Tucson, Arizona, ARMA-87-1213.

Gangi AF (1978) Variation of whole and fractured porous rock permeability with confining pressure. Int J Rock Mech Min Sci Geomech Abstr 15(5):249-257. https://doi.org/10.1016/01489062(78)90957-9

Gentier S, Lamontagne E, Archambault G, Riss J (1997) Anisotropy of flow in a fracture undergoing shear and its relationship to the direction of shearing and injection pressure. Int J Rock Mech Min Sci 34(3-4):94.e1-94.e12. https://doi.org/10.1016/S13651609(97)00085-3

Glover PWJ, Matsuki K, Hikima R, Hayashi K (1997) Fluid flow in fractally rough synthetic fractures. Geophys Res Lett 24(14):1803-1806. https://doi.org/10.1029/97GL01670

Golfier F, Zarcone C, Bazin B, Lenormand R, Lasseux D, Quintard M (2002) On the ability of a Darcy-scale model to capture wormhole formation during the dissolution of a porous media. J Fluid 
Mech 457:213-254. https://doi.org/10.1017/S00221120020077 35

Grasselli G (2001) Shear Strength of Rock Joints Based on Quantified Surface Description. Dissertation, Ecole Polytechnique Federale de Lausanne

Grasselli G, Wirth J, Egger P (2002) Quantitative three-dimensional description of a rough surface and parameter evolution with shearing. Int J Rock Mech Min Sci 39(6):789-800. https://doi. org/10.1016/S1365-1609(02)00070-9

Greenwood JA, Williamson JBP, Bowden FP (1966) Contact of nominally flat surfaces. Proc R Soc Lond Ser A Math Phys Sci 295(1442):300-319. https://doi.org/10.1098/rspa.1966.0242

Gutierrez M, Øino LE, Nygård R (2000) Stress-dependent permeability of a de-mineralised fracture in shale. Mar Pet Geol 17(8):895907. https://doi.org/10.1016/S0264-8172(00)00027-1

Hakami E, Larsson E (1996) Aperture Measurements and Flow Experiments on a Single Natural Fracture. Int J Rock Mech Min Sci 33(4):395-404. https://doi.org/10.1016/0148-9062(95) 00070-4

Hopkins DL, Cook NGW, Myer L (1987) Fracture stiffness and aperture as a function of applied stress and contact geometry. In: Farmer IW, Daemen JJ, Desai CS, Glass CE, Neuman SP (eds) Rock Mechanics: Proceedings of the 28th U.S. Symposium, CRC Press, Tucson, pp 673-680

Indraratna B, Ranjith PG, Gale W (1999) Single phase water flow through rock fractures. Geotech Geol Eng 17(3):211-240. https://doi.org/10.1023/a:1008922417511

Inoue J, Sugita H (2003) Fourth-order approximation of fluid flow through rough-walled rock fracture. Water Resour Res. https:// doi.org/10.1029/2002WR001411

Iwano M, Einstein HH (1995) Laboratory experiments on geometric and hydromechanical characteristics of three different fractures in granodiorite. In: Proceedings of the 8th ISRM Congress, Tokyo, Japan. ISRM-8CONGRESS-1995-151

Jacobs TDB, Junge T, Pastewka L (2017) Quantitative characterization of surface topography using spectral analysis. Surf Topogr Metrol Prop. https://doi.org/10.1088/2051-672X/aa51f8

Jang J, Narsilio GA, Santamarina JC (2011) Hydraulic conductivity in spatially varying media-a pore-scale investigation. Geophys J Int 184(3):1167-1179. https://doi.org/10.1111/j.1365246X.2010.04893.x

Katz AJ, Thompson AH (1985) Fractal sandstone pores: implications for conductivity and pore formation. Phys Rev Lett 54(12):1325-1328. https://doi.org/10.1103/PhysRevLett.54. 1325

Keller A (1998) High resolution, non-destructive measurement and characterization of fracture apertures. Int J Rock Mech Min Sci 35(8):1037-1050. https://doi.org/10.1016/S0148-9062(98) 00164-8

Kim S, Santamarina JC (2016) Geometry-coupled reactive fluid transport at the fracture scale: application to $\mathrm{CO} 2$ geologic storage. Geofluids 16(2):329-341. https://doi.org/10.1111/gfl.12152

Kling T, Vogler D, Pastewka L, Amann F, Blum P (2018) Numerical simulations and validation of contact mechanics in a granodiorite fracture. Rock Mech Rock Eng 51(9):2805-2824. https://doi.org/ 10.1007/s00603-018-1498-x

Lanaro F (2000) A random field model for surface roughness and aperture of rock fractures. Int J Rock Mech Min Sci 37:1195-1210. https://doi.org/10.1016/S1365-1609(00)00052-6

Leach R (2011) Optical measurement of surface topography. Springer, Berlin, Heidelberg. https://doi.org/10.1007/978-3-642-12012-1

Lee JJ, Bruhn RL (1996) Structural anisotropy of normal fault surfaces. J Struct Geol 18(8):1043-1059. https://doi.org/10.1016/ 0191-8141(96)00022-3
Lee HS, Cho TF (2002) Hydraulic characteristics of rough fractures in linear flow under normal and shear load. Rock Mech Rock Eng 35(4):299-318. https://doi.org/10.1007/s00603-002-0028-y

Li B, Jiang Y, Koyama T, Jing L, Tanabashi Y (2008) Experimental study of the hydro-mechanical behavior of rock joints using a parallel-plate model containing contact areas and artificial fractures. Int J Rock Mech Min Sci 45(3):362-375. https://doi.org/ 10.1016/j.ijrmms.2007.06.004

Li B, Zhao Z, Jiang Y, Jing L (2015) Contact mechanism of a rock fracture subjected to normal loading and its impact on fast closure behavior during initial stage of fluid flow experiment. Int $\mathbf{J}$ Numer Anal Meth Geomech 39(13):1431-1449. https://doi.org/ $10.1002 /$ nag. 2365

Lomize GM (1951) Flow in fractured rocks (in russian). Gosenergoizdat, Moscow, p 127

Magsipoc E, Zhao Q, Grasselli G (2020) 2D and 3D roughness characterization. Rock Mech Rock Eng 53:1495-1519. https://doi.org/ 10.1007/s00603-019-01977-4

Majumdar A, Bhushan B (1990) Role of fractal geometry in roughness characterization and contact mechanics of surfaces. J Tribol 112(2):205-216. https://doi.org/10.1115/1.2920243

Makurat A, Barton N, Rad NS, Bandis S (1990) Joint conductivity variation due to normal and shear deformation. In: Barton $\mathrm{N}$, Stephansson O (eds) Proceedings of the International Symposium on Rock Joints, A.A. Balkema, Rotterdam, pp 535-540

Mandelbrot BB, Passoja DE, Paullay AJ (1984) Fractal character of fracture surfaces of metals. Nature 308:721-722. https://doi.org/ 10.1038/308721a0

Matsuki K, Chida Y, Sakaguchi K, Glover PWJ (2006) Size effect on aperture and permeability of a fracture as estimated in large synthetic fractures. Int J Rock Mech Min Sci 43(5):726-755. https:// doi.org/10.1016/j.ijrmms.2005.12.001

Matsuki K, Kimura Y, Sakaguchi K, Kizaki A, Giwelli A (2010) Effect of shear displacement on the hydraulic conductivity of a fracture. Int J Rock Mech Min Sci 47(3):436-449. https://doi.org/ 10.1016/j.ijrmms.2009.10.002

Nemoto K, Watanabe N, Hirano N, Tsuchiya N (2009) Direct measurement of contact area and stress dependence of anisotropic flow through rock fracture with heterogeneous aperture distribution. Earth Planet Sci Lett 281(1):81-87. https://doi.org/10.1016/j. eps1.2009.02.005

Nguyen TS, Selvadurai APS (1998) A model for coupled mechanical and hydraulic behavior of a rock joint. Int J Numer Anal Meth Geomech 22(1):29-48. https://doi.org/10.1002/(SICI)10969853(199801)22:1\%3c29::AID-NAG907\%3e3.0.CO;2-N

Nishiyama S, Ohnishi Y, Ito H, Yano T (2014) Mechanical and hydraulic behavior of a rock fracture under shear deformation. Earth Planets Space 66(1):108. https://doi.org/10.1186/ 1880-5981-66-108

Odling NE (1994) Natural fracture profiles, fractal dimension and joint roughness coefficients. Rock Mech Rock Eng 27(3):135-153. https://doi.org/10.1007/bf01020307

Ogilvie SR, Isakov E, Glover PWJ (2006) Fluid flow through rough fractures in rocks. II: a new matching model for rough rock fractures. Earth Planet Sci Lett 241(3):454-465. https://doi.org/10. 1016/j.epsl.2005.11.041

Olsson WA (1992) The effect of slip on the flow of fluid through a fracture. Geophys Res Lett 19(6):541-543. https://doi.org/10. 1029/92GL00197

Olsson R, Barton N (2001) An improved model for hydromechanical coupling during shearing of rock joints. Int J Rock Mech Min Sci 38(3):317-329. https://doi.org/10.1016/S1365-1609(00)00079-4

Oron AP, Berkowitz B (1998) Flow in rock fractures: the local cubic law assumption reexamined. Water Resour Res 34(11):28112825. https://doi.org/10.1029/98WR02285 
Patir N, Cheng H (1978) An average flow model for determining effects of three-dimensional roughness on partial hydrodynamic lubrication. J Lubr Technol 100(1):12-17. https://doi.org/10.1115/1. 3453103

Patton FD (1966) Multiple modes of shear failure in rock. In: Proceedings of the 1st Congress International Society of Rock Mechanics, Lisbon, Portugal, 25 September, pp 509-513

Plesha ME (1987) Constitutive models for rock discontinuities with dilatancy and surface degradation. Int J Numer Anal Meth Geomech 11(4):345-362. https://doi.org/10.1002/nag.16101 10404

Plummer L, Wigley T, Parkhurst D (1978) The kinetics of calcite dissolution in $\mathrm{CO} 2$-water systems at 5 degrees to 60 degrees $\mathrm{C}$ and 0.0 to $1.0 \mathrm{~atm}$ CO 2. Am J Sci 278(2):179-216. https://doi.org/ 10.2475/ajs.278.2.179

Power WL, Durham WB (1997) Topography of natural and artificial fractures in granitic rocks: implications for studies of rock friction and fluid migration. Int J Rock Mech Min Sci 34(6):979989. https://doi.org/10.1016/S1365-1609(97)80007-X

Power WL, Tullis TE (1991) Euclidean and fractal models for the description of rock surface roughness. J Geophys Res 96(B1):415-424. https://doi.org/10.1029/90JB02107

Pyrak-Nolte LJ, Morris JP (2000) Single fractures under normal stress: the relation between fracture specific stiffness and fluid flow. Int J Rock Mech Min Sci 37(1):245-262. https://doi.org/10.1016/ S1365-1609(99)00104-5

Pyrak-Nolte LJ, Nolte DD (2016) Approaching a universal scaling relationship between fracture stiffness and fluid flow. Nat Commun 7:10663. https://doi.org/10.1038/ncomms10663

Pyrak-Nolte LJ, Myer LR, Cook NGW, Witherspoon PA (1987) Hydraulic and mechanical properties of natural fractures in low permeability rock. In: Herget G, Vongpaisal S (eds) Proceedings of the 6th ISRM Congress, A.A. Balkema, Rotterdam, pp 225-231

Raven KG, Gale JE (1985) Water flow in a natural rock fracture as a function of stress and sample size. Int J Rock Mech Min Sci Geomech Abstr 22(4):251-261. https://doi.org/10.1016/01489062(85)92952-3

Rutqvist J, Wu YS, Tsang CF, Bodvarsson G (2002) A modeling approach for analysis of coupled multiphase fluid flow, heat transfer, and deformation in fractured porous rock. Int J Rock Mech Min Sci 39(4):429-442. https://doi.org/10.1016/S13651609(02)00022-9

Saeb S, Amadei B (1992) Modelling rock joints under shear and normal loading. Int J Rock Mech Min Sci Geomech Abstr 29(3):267278. https://doi.org/10.1016/0148-9062(92)93660-C

Sayles RS, Thomas TR (1978) Surface topography as a nonstationary random process. Nature 271(5644):431-434. https://doi.org/10. 1038/271431a0

Sharifzadeh M, Mitani Y, Esaki T (2008) Rock joint surfaces measurement and analysis of aperture distribution under different normal and shear loading using GIS. Rock Mech Rock Eng 41(2):299_ 323. https://doi.org/10.1007/s00603-006-0115-6

Shin H, Santamarina JC (2019) An implicit joint-continuum model for the hydro-mechanical analysis of fractured rock masses. Int J Rock Mech Min Sci 119:140-148. https://doi.org/10.1016/j. ijrmms.2019.04.006

Souley M, Lopez P, Boulon M, Thoraval A (2015) Experimental hydromechanical characterization and numerical modelling of a fractured and porous sandstone. Rock Mech Rock Eng 48(3):11431161. https://doi.org/10.1007/s00603-014-0626-5

ASTM Standard D7012-14e1 (2014) Compressive strength and elastic moduli of intact rock core specimens under varying states of stress and temperatures. ASTM International, West Conshohocken. https://doi.org/10.1520/D7012-14E01
Swan G (1983) Determination of stiffness and other joint properties from roughness measurements. Rock Mech Rock Eng 16(1):1938. https://doi.org/10.1007/bf01030216

Tarolli P (2014) High-resolution topography for understanding earth surface processes: opportunities and challenges. Geomorphology 216:295-312. https://doi.org/10.1016/j.geomorph.2014.03.008

Taron J, Elsworth D, Min KB (2009) Numerical simulation of thermalhydrologic-mechanical-chemical processes in deformable, fractured porous media. Int J Rock Mech Min Sci 46(5):842-854. https://doi.org/10.1016/j.ijrmms.2009.01.008

Teufel LW (1987) Permeability changes during shear deformation of fractured rock. In: Farmer IW, Daemen JJ, Desai CS, Glass CE, Neuman SP (eds) Rock Mechanics: Proceedings of the 28th U.S. Symposium, CRC Press, Tucson, pp 473-480

Tezuka K, Tamagawa T, Watanabe K (2005) Numerical Simulation of Hydraulic Shearing in Fractured Reservoir. In: Horne R, Okandan E (eds) Proceedings of the World Geothermal Congress 2005, International Geothermal Association, Antalya

Thomas TR (1998) Rough Surfaces. Imperial College Press, London

Tsang YW, Witherspoon PA (1981) Hydromechanical behavior of a deformable rock fracture subject to normal stress. J Geophys Res Solid Earth 86(B10):9287-9298. https://doi.org/10.1029/ JB086iB10p09287

Tuncay E, Hasancebi N (2009) The effect of length to diameter ratio of test specimens on the uniaxial compressive strength of rock. Bull Eng Geol Env 68(4):491-497. https://doi.org/10.1007/ s10064-009-0227-9

Vogler D, Settgast RR, Annavarapu C, Madonna C, Bayer P, Amann F (2018) Experiments and simulations of fully hydro-mechanically coupled response of rough fractures exposed to high-pressure fluid injection. J Geophys Res Solid Earth 123(2):1186-1200. https://doi.org/10.1002/2017jb015057

Walsh JB (1981) Effect of pore pressure and confining pressure on fracture permeability. Int J Rock Mech Min Sci Geomech Abstr 18(5):429-435. https://doi.org/10.1016/0148-9062(81)90006-1

Walsh R, McDermott C, Kolditz O (2008) Numerical modeling of stress-permeability coupling in rough fractures. Hydrogeol J 16(4):613-627. https://doi.org/10.1007/s10040-007-0254-1

Watanabe N, Hirano N, Tsuchiya N (2008) Determination of aperture structure and fluid flow in a rock fracture by high-resolution numerical modeling on the basis of a flow-through experiment under confining pressure. Water Resour Res. https://doi.org/10. 1029/2006wr005411

Wilbur C, Amadei B (1990) Flow pump measurements of fracture transmissivity as a function of normal stress. In: Hustrulid WA, Johnson GA (eds) Rock mechanics contributions and challenges: Proceedings of the 31st U.S. Symposium, CRC Press, London, pp 621-627

Witherspoon PA, Wang JSY, Iwai K, Gale JE (1980) Validity of Cubic Law for fluid flow in a deformable rock fracture. Water Resour Res 16(6):1016-1024. https://doi.org/10.1029/WR016i006p 01016

Xiong F, Jiang Q, Chen M (2018) Numerical investigation on hydraulic properties of artificial-splitting granite fractures during normal and shear deformations. Geofluids. https://doi.org/10.1155/2018/ 9036028 (Article ID 9036028)

Yeo IW, de Freitas MH, Zimmerman RW (1998) Effect of shear displacement on the aperture and permeability of a rock fracture. Int J Rock Mech Min Sci 35(8):1051-1070. https://doi.org/10. 1016/S0148-9062(98)00165-X

Zhao J (1997) Joint surface matching and shear strength part A: joint matching coefficient (JMC). Int J Rock Mech Min Sci 34(2): 173178. https://doi.org/10.1016/S0148-9062(96)00062-9

Zhou H, Abdelaziz A, Grasselli G (2018) Rock dilation and its effect on fracture transmissivity. Proceedings of the 
Unconventional Resources Technology Conference, Houston, Texas. URTEC-2903018-MS

Zimmerman RW, Bodvarsson GS (1996) Hydraulic conductivity of rock fractures. Transp Porous Media 23(1):1-30. https://doi.org/ $10.1007 / \mathrm{bf00145263}$
Publisher's Note Springer Nature remains neutral with regard to jurisdictional claims in published maps and institutional affiliations. 